De l'amitié et des frères : l'Épître 45 des Rasā'il IHwān al-Ṣafā'.

Présentation et traduction annotée

\title{
Cécile Bonmariage
}

\section{CpenEdition}

\section{Journals}

Édition électronique

URL : http://journals.openedition.org/beo/78

DOI : $10.4000 /$ beo.78

ISBN : 978-2-35159-316-5

ISSN : 2077-4079

\section{Éditeur}

Presses de l'Institut français du Proche-Orient

\section{Édition imprimée}

Date de publication : 1 septembre 2009

Pagination : 315-350

ISBN : 978-2-35159-143-7

ISSN : 0253-1623

Référence électronique

Cécile Bonmariage, «De l'amitié et des frères : I'Épître 45 des Rasāil Ihwān al-Șafā'. », Bulletin d'études orientales [En ligne], Tome LVIII | Septembre 2009, mis en ligne le 01 septembre 2010, consulté le 01 mai 2019. URL : http://journals.openedition.org/beo/78; DOI : 10.4000/beo.78 
DE L'AMITIÉ ET DES FRÈRES : L'ÉPITTRE 45 DES RASĀ'IL IHWĀN AL-ȘAFĀ'.

Présentation et traduction annotée

Cécile BONMARIAGE

Chercheur qualifiée du F.N.R.S.

PRÉSENTATION

L'Épître 45 des Rasā’il Ihwān al-Ṣafā' s'est signalée très tôt aux chercheurs du fait d'éléments importants qu'elle contient pour la datation de ce texte: une mention de la théorie du bond, initiée par le mu'tazilite al-Naẓzām (mort entre 220/835 et 230/845), et la citation de vers extraits d'un poème composé par al-Mutanabbī en 347/958 ${ }^{1}$. Elle a aussi été remarquée pour son intérêt dans l'étude de la formation et de la diffusion du Sirr al-asrār (le Secretum secretorum). On trouve dans la version longue de ce dernier texte, en effet, plusieurs points également présents dans l'Épître 45 , notamment une chaîne de vices ${ }^{2}$ et le passage sur les quatre niveaux de l'âme humaine que nous analyserons bientôt plus en détail ${ }^{3}$.

Ainsi que son titre l'indique ( « Du comment des relations qu'entretiennent entre eux les Frères de la Pureté, de leur entraide et de la sincérité de la sollicitude et de l'affection qu'ils ont les uns envers les autres »), le but principal de cette épître est de décrire la communauté des Frères de la Pureté et son mode de fonctionnement. Elle aborde tour à tour le mağlis des Frères, - ce lieu de réunion, sorte de "salon philosophique » sur la description duquel s'ouvre l'épître -, le recrutement, l'entraide matérielle et spirituelle au sein du groupe, l'enseignement et les relations maître-disciple, et enfin les différents degrés d'accomplissement atteints par les Frères dans leur cheminement vers le vrai.

Tout au long de l'épître, l'on perçoit également un autre aspect du fonctionnement de la communauté des Frères de la Pureté : la variété des sources auxquelles elle se réfère,

1. Rasā’il Ihwwān al-Ṣafā', Beyrouth, 1957 (désormais cité Rasā’il), t. IV, p. 50 et 47 respectivement. Ces éléments ont été interprétés en divers sens suivant que les auteurs souhaitaient avancer ou retarder la date de rédaction des Épitres et privilégier une rédaction longue ou courte du recueil. Sur la datation et le ou les auteurs des Rasāill, voir G. de Callatä̈, Ikhwan al-Safa', Oxford, Oneworld, 2005, p. 3-8. On y lit qu'il est à présent généralement admis que les Épitres ont été écrites dans les années 970-980.

2. Voir Rasā’il, t. IV, p. 47 et Sirr al-asrār, éd. 'A. Badawī, in Fontes grcecce doctrinarum politicarum islamicarum, Le Caire, 1954 p. 75-76.

3. Sirr al-asrār, éd. 'A. Badawī, p. 131-132 et Rasā’il, t. IV, p. 57. Voir A. A. Verdenius, Jacob van Maerlant's Heimelijkheid der Heimelijkheden, Amsterdam, 1917 ; M. Manzalou, « The pseudo-Aristotelian Kitāb Sirr al-asrār », in Oriens, 23-24 (1974), p. 142-257 ; M. GRIGNASCHI, « Remarques sur la formation et l'interprétation du Sirr al-asrār », in Pseudo-Aristotle The Secret of Secrets. Sources and Influences, éd. W.F. Ryan et Ch. B. Schmitt, Londres, 1982, p. 3-33. 
discernable de façon directe dans le passage qui énumère les quatre sortes de « livres » sur lesquels se basent l'enseignement et le savoir des Frères ${ }^{4}$, mais aussi de façon indirecte, par les citations variées qui émaillent l'épître, qui font référence à des penseurs grecs (Socrate, Pythagore) ${ }^{5}$, à deux figures emblématiques de la sagesse indienne (Bilawhar et Būdāsf) ${ }^{6}$, ou encore à Jésus (al-Masīh) s'adressant aux apôtres ?

Deux points retiendront plus particulièrement notre attention ici. Nous montrerons d'abord comment la description de la communauté des Frères présentée dans cette épître est l'occasion d'un véritable traité sur l'amitié, tout à fait dans l'esprit d'autres ouvrages sur le sujet rédigés à la même époque. Nous analyserons ensuite de plus près le passage où est décrite la hiérarchie des Frères, qui, en établissant un parallèle entre les puissances de l'âme et l'âge auquel elles apparaissent, présente en même temps une théorie des âges de l'homme, et, en associant une appellation spécifique pour chaque degré, livre une clef de lecture originale des Rasāil.

\section{UN TRAITÉ SUR L’AMITIÉ}

Dès les premières pages consacrées au choix d'un nouveau frère, après la description du mağlis et des connaissances qui y sont enseignées, l'on s'aperçoit que la communauté des Frères de la Pureté est conçue, un peu à la manière des écoles philosophiques de l'Antiquité, comme se fondant sur l'amitié. C'est l'amitié qui préside au recrutement, qui se fait par affiliation, l'amitié qui régit les relations entre frères dans leur apport à la communauté, chacun selon ses moyens, l'amitié qui fonde les rapports entre maîtres et disciples, l'amitié qui cimente l'unité à laquelle aspire la communauté toute entière. Voici à grands traits ce que l'épître nous apprend concernant la façon dont les Ihwān pensent cette question.

\section{Le choix et la conservation des amis}

Tout d'abord, c'est pour les Ihwān le constat de la nécessité de l'entraide entre les hommes pour leur bien-être à tous qui est le fondement de la recherche de l'ami. Cette nécessité est maintes fois soulignées dans les Rasāil ${ }^{8}$, notamment dans le passage suivant, extrait de l'Épitre sur la géométrie, où l'on retrouve un écho de l'adage hippocratique ars longa, vita brevis : «Sache-le, frère, [...] l'homme isolé ne peut mener qu'une existence misérable. Il a besoin pour mener une existence bonne [...] de nombreux arts qu'un seul homme ne peut atteindre tous, parce que la vie est courte et les arts nombreux. C'est pourquoi en chaque ville ou village se réunissent des gens nombreux, pour s'entraider les uns les autres ${ }^{9}$.»

Ce constat est vrai pour la vie de ce monde comme pour le salut final dans l'au-delà. Pensant l'amitié dans la perspective de la recherche du salut, les Frères considèrent les

\footnotetext{
4. Rasā'il, t. IV, p. 42-43.

5. Ibid., p. 58.

6. Ibid.

7. Ibid., p. 53 et 58 .

8. Notamment dans l'Épître 48, parallèle à l'Épître 45. Voir Rasā’il, t. IV, p. 169-170.

9. Rasā'il, t. I, p. 99-100 (Épître sur la géométrie).
} 
amis non seulement comme un agrément essentiel pour cette vie-ci, mais comme l'aide indispensable à la sortie vers l'autre monde, par la mise en commun des biens et de la connaissance, que ce soit les sciences de la sagesse, "qui permettent d'atteindre le bienêtre des corps dans la demeure des organismes et dans le monde de la génération et de la corruption ", ou les sciences des prophètes, amenant au «bien-être de l'âme dans la demeure du retour ${ }^{10} »$.

Concernant le choix des amis, les Ihwān insistent sur le fait que tous les caractères ne sont pas aptes à l'amitié parfaite. Reprenant des éléments présents dans l'épitre sur les caractères ${ }^{11}$, ils posent que le caractère est le fruit pour une part de traits innés (sous l'influence des astres et du tempérament, lui-même déterminé par les conjonctions astrales), renforcés ou non par les habitudes et les croyances dans lesquelles on est éduqué ${ }^{12}$. Une fois bien ancré, le caractère est difficilement améliorable, et il est donc important de reconnaître les signes d'un caractère contraire. Aussi les Ihwwān s'attachentils à dénombrer une série de caractères opposés entre eux, entre lesquels aucune amitié ne pourra se nouer, et à présenter l'enchaînement qui, de cette opposition dans les caractères, conduit à l'hostilité ouverte ${ }^{13}$.

Au delà de cette distinction entre caractères aptes et inaptes à l'amitié, les Ihwān tracent une distinction claire entre amitiés ayant une cause en dehors de la relation même, qui sont les amitiés fondées sur le besoin immédiat, et l'amitié véritable et parfaite qui lie entre eux les Frères. Les premières se nouent en vue d'un but précis, qui relève généralement de ce monde, et ne durent que le temps du besoin. L'amitié véritable, par contre, est sans limite, parce qu'elle est fondée sur une communauté totale, les amis devenant comme « une seule âme en deux organismes se faisant face ${ }^{14} »$. On peut voir dans cette formule une reprise du topos grec de l'ami comme allos autos, expression qui, en arabe, est rendue par différentes périphrases comme "quelqu'un qui est toi-même, mais qui, en tant qu'individu, est différent de toi ${ }^{15}$ », ainsi que l'écrit Tawhīīi (m. 1023), ou encore quelqu'un « qui est toi, sauf qu'il est différent de toi (gayruka) ${ }^{16} »$, comme dit Bīrūnī (m. 1048) ${ }^{17}$.

\footnotetext{
10. Rasā'il, t. IV, p. 142.

11. Rasāil, t. I, p. 296-389 (Épître 9), en particulier p. 299-307.

12. Les Ihwān n'insistent pas ici sur l'influence de la région et du climat dont il est question dans l'Épitre des caractères. Voir Rasā’il, t. I, p. 302-305.
}

13. Rasā'il, t. IV, p. 47.

14. Rasā'il, t. IV, p. 49. On retrouve p. 48 une expression très semblable : « Cela parce qu'ils pensent et croient qu'ils sont une seule âme en des organismes dispersés ».

15. TAWHī̄īī, Risāla fỉ l-șadāqa, éd. Ǧawā'ib, p. 26 ; cité et traduit par M. Bergé, Pour un humanisme vécu : Abū Hayyān al-Tawhīì̄, Damas, 1979, p. 324. On trouvera dans la dernière discussion des Muqābasāt de Tawhīì̄ la relation d'une discussion sur cette conception de l'ami comme « un autre qui est toi-même » (āhar huwa anta). Voir al-Muqābasāt, nº 106 (éd. M. T. Ḥusayn, Bagdad, 1970, p. 449-454).

16. BīrūNī, Kitāb al-ğamāhīr fì márifat al-ğawāhir, Beyrouth, 1984 (3e éd.), p. 18. On trouvera une traduction du passage dont cette expression est extraite note 125.

17. Sur la définition de l'ami comme alter ego dans la tradition arabe, voir F. RosentHAL, «"I am you" - Individual piety and society in Islam », in Individualism and Conformity in Classical Islam, éd. A. Banani et S. Vryonis, Wiesbaden, 1977, p. 33-60. 
Pour saisir plus pleinement l'expression utilisée dans les Rasā'il, il faut la replacer toutefois dans la perspective de la théorie de l'Âme universelle défendue par les Ihwān. Pour ceux-ci, ainsi qu'ils l'expliquent dans l'Épître 42 notamment, l'ensemble des individus partagent une forme unique, l'Âme universelle. Chaque homme a ainsi en lui une part de cette Âme, et celle-ci est pour chacun de ses fragments comme notre âme est par rapport aux membres de notre corps ${ }^{18}$. En disant des amis véritables qu'ils sont « une seule âme en deux organismes se faisant face », c'est sans doute aussi cela que les Ihwān entendent.

C'est cette amitié où l'ami est un autre soi-même qui est la base même de la communauté des Frères de la Pureté, dont les membres visent à être « comme un seul homme [...], et comme une seule âme dans l'ensemble de ce qu'ils entreprennent en vue de ce qu'ils visent, qui est de faire triompher la religion et de rechercher l'au-delà ${ }^{19}$ ». Une fois nouée, une telle amitié doit être entretenue et nourrie, notamment en préférant ce frère à toute autre relation, ce que développe un long passage consacré à la conservation de l'amitié ${ }^{20}$.

\section{L'amitié dans les rapports maître-disciple et dans l'enseignement}

C'est par la connaissance véritable que l'on parvient au salut selon les Ihwān, en « se réveillant du sommeil de l'ignorance et de l'assoupissement de la négligence ", comme le répètent souvent les Rasā’il. Aussi est-ce particulièrement dans l'enseignement que va se montrer l'entraide entre Frères. Le passage consacré au choix du maitre ${ }^{21}$ est surtout l'occasion de dénigrer les faux savants qui parlent de toutes sortes de choses complexes alors qu'ils ne connaissent pas la base de toute science, c'est-à-dire eux-mêmes, tel un affamé qui nourrirait les gens, ou quelqu'un qui est malade lui-même et prétendrait soigner les autres, selon l'image donnée dans l'Épître $48^{22}$.

Par les exemples choisis ici par les Ihwān (la théorie du bond, le feu qui ne brûle pas, etc. $\left.{ }^{23}\right)$, on voit que ceux qu'ils visent sont premièrement ceux qui s'adonnent au kaläm. La théorie du bond, selon laquelle un mobile « peut passer du premier point au troisième sans passer par le point intermédiaire ${ }^{24} »$, a en effet été énoncée d'abord par al-Naẓā̄m (mort entre 835 et 845 ) pour donner une explication du mouvement dans sa physique

18. Voir notamment Rasā'il, t. III, p. 426. Sur ceci, voir Y. MARQUET, La philosophie des Ihwān al-Ṣafä'. Alger, 1973, p. 366.

19. Rasā’il, t. I, p. 181-182 (Épître sur la géographie).

20. Rasāil, t. IV, p. 47-49.

21. Rasā'il, t. IV, p. 49-51.

22. Rasā'il, t. IV, p. 169. Le passage se lit : « [Ils sont semblables] à celui qui nourrit les gens alors qu'il est lui-même affamé, ou qui habille les autres alors que lui-même est nu, comme celui qui soigne les gens alors qu'il est malade, et comme celui qui guide les gens sur la voie alors qu'il ne connaît pas le chemin de sa maison ». En un passage parallèle, les Ihwān disent encore : « Il est comme celui qui guiderait autrui alors que lui-même est égaré » (Rasāill, t. III, p. 372).

23. Rasāill, t. IV, p. 50-51.

24. Cité dans Š ShRASTĀNĪ, Livre des religions et des sectes, vol. I, trad. D. Gimaret et G. Monnot, Louvain, 1986, p. 206, n. 33. Ibn Hazm (m. 1064) l'explique de la façon suivante : « Le mobile sur la surface d'un corps va d'un lieu à un autre lieu, et entre les deux lieux, il y a des lieux que le mobile n'a ni parcourus, ni longés, ni occupés » (al-Fișal, éd. M. I. Nașr et 'A. 'Umayra, Djedda, 1982, v. 5, p. 189). 
qui nie l'atome ; elle a ensuite été reprise par une lignée de penseurs au sein du kalām ${ }^{25}$. L'exemple du feu peut certes être compris comme une allusion à une théorie de la vue de type platonicien, le rayon rendant la vue possible étant décrit en effet par Platon comme une «sorte de feu qui n'est pas capable de brûler, mais seulement de fournir une douce lumière ${ }^{26} »$, mais c'est surtout un des exemples les plus communs dans l'explication de la théorie de l'engendrement (tawallud) des actions développée dans le kalām ${ }^{27}$.

La critique des négateurs de l'astrologie peut aussi être envisagée comme visant les mutakallimūn: parmi les mu'tazilites, 'Abd al-Ǧabbār est connu pour son opposition à l'astrologie ${ }^{28}$, et al-Aš'arī en est également un pourfendeur ${ }^{29}$. Mais elle pourrait aussi avoir pour cible les gens de droit (légalistes, fuqahā'), comme dans la troisième épître où les Ihwān évoquent les gens du fiqh qui ne jugent pas bon de s'occuper de l'astrologie : « Sache que les légalistes et les traditionnistes, les pieux et les dévots ont proscrit l'étude de l'astrologie. Ils l'ont proscrit seulement parce que l'astrologie est une partie de la science philosophique, et qu'ils abhorrent l'étude des sciences philosophiques pour les néophytes et les jeunes gens, et tout qui ne connaît pas la science de la religion et qui ne connaît pas la mesure dont il a besoin des statuts de la loi (šarĩa) ${ }^{30}$. »

Concernant l'enseignement même, l'Épître 45 nous apprend surtout le peu de foi des Ihwān dans l'enseignement comme "redressement » d'un caractère déjà tordu par une naissance sous de mauvais auspices ou comme un apprentissage accessible à tout âge : il s'agit plutôt de faire grandir les «bonnes pousses ", en choisissant des disciples jeunes et bien nés, au sens de nés sous l'influence positive des astres, qui leur garantit une nature équilibrée et des capacités optimales à recevoir l'enseignement ${ }^{31}$.

\section{Un thème cher au $X^{e}$ siècle}

Ce que disent ici les Ihwān concernant l'amitié n'a rien de particulièrement inédit. Le thème même de l'amitié, comme celui des relations entre maître et disciple et des qualités de chacun - et comme aussi la question de l'organisation des cités, dont l'absence dans

25. Voir A. Dhahanı, The Physical Theory of Kalām, Leyde, 1994, p. 161 et 176-181, ainsi que J. van Ess, Theology and Science. The Case of Abū Ishāq an-Nazzāam, Ann Arbor, [1978 ?], spécialement p. 6-9, ainsi que son Theologie und Gesellschaft im 2. und 3. Jahrhundert Hidschra, Berlin, 1991-1995, index, s.v. tafra, spéc. Bd III (1992), p. 309 et sq.

26. Timée, $45 \mathrm{~b}$ et sq.

27. Voir par exemple Iвn Hazm, al-Fișal, vol. 5, p. 181.

28. Voir S. M. STERN, « New information about the authors of the Epistles of the Sincere Brethren », in Islamic Studies, III (1964), p. 158 (réédité in Studies in Early Ismā'îlism, Jérusalem, 1983).

29. Pour un exposé plus détaillé des positions de différents penseurs à ce propos, voir M. Ullmann, Die Naturund Geheimwissenschaften im Islam, Leyde, 1972, p. 274-275, ainsi que J. vAN Ess, Theologie und Gesellschaft, index, s.v. «Astrologie ».

30. Rasā̉il, t. I, p 157.

31. Pour une vue plus générale sur la conception qu'ont les Ihwān de l'éducation et de l'enseignement, voir A. TiBAwı, "The idea of guidance in Islam », in Islamic Quarterly, III (1956), p. 139-156; « Philosophy of Muslim education », in Islamic Quarterly, IV (1957), p. 79-89 ; "Some educational terms in the Rasā'il Ihwān al-Șafä' », in Islamic Quarterly, V (1959), p. 55-60. Voir aussi A. NANJI, « On the acquisition of knowledge », in The Muslim World, LXVI (1976), p. 263271. 
l'Épître 45 peut paraître étonnante ${ }^{32}$-, sont très présents dans la littérature du $\mathrm{X}^{\mathrm{e}}$ siècle dans le milieu dans lequel les Rasā’il semblent avoir vu le jour. Les traités sur l'amitié et sur le caractère foisonnent à l'époque, tels la Risālat al-șadāqa wa-l-șadīq de Tawhīdī, les chapitres consacrés à cette question dans les Muqābasāt ${ }^{33}$ du même auteur, ou plus tard, mais par quelqu'un qui fréquentait les mêmes milieux, le Tahdīib al-ahlāq de Miskawayh (m. 1030), et les passages sur l'amitié dans les questions-réponses entre Tawhīīi et Miskawayh du Hawāmil wa-l-šawāmil ${ }^{34}$.

On y retrouve des éléments semblables sur le fond. On l'a vu brièvement déjà pour la définition de l'ami comme un autre soi-même. Un autre exemple est la distinction entre amitié qui se lie pour une cause déterminée et amitié véritable, qui se retrouve dans le Hawāmil wa-l-šawāmil sous la forme d'une distinction entre amitiés accidentelles et amitiés essentielles ${ }^{35}$. Mais on y reconnait également certains traits de style des écrits des Ihwān. Ainsi les séries de courtes phrases conditionnelles de notre épître, comme dans le passage suivant: «Si tu es absent, ils te protègent; si tu dépéris, ils te soutiennent; et s'ils te voient un ennemi, ils le matent ${ }^{36}$ ", trouvent un écho dans ce passage de la Risālat al-ṣadāqa wa-l-ṣadīq de Tawhīdī : "Si tu t'absentes, il te suit; si tu es présent, il te défend; si tu es maltraité, il te traite avec douceur ${ }^{37}$. " Tawhīdī et Miskawayh montrent également un certain penchant pour l'énumération des caractères aussi présent dans les Rasā'il, les auteurs se laissant aller au plaisir des mots.

Par contre, on ne retrouve pas chez les Ihwān les références au fond culturel arabe sur l'amitié, qui est la base même de la Risālat al-șadāqa de Tawhīdī qui se présente plus comme une anthologie sur le thème que comme un véritable traité. On ne retrouve pas non plus le pessimisme que l'on peut déceler chez ce dernier, dans la Risālat al-șadāqa, mais aussi dans le chapitre 106 des Muqābasāt, consacré à l'amitié, qui commence par la constatation que la définition de l'ami comme un autre soi-même est valide, mais n'a rien qui lui corresponde dans la réalité : un tel ami n'existe pas ${ }^{38}$. Chez les Ihwān au contraire, la véritable amitié existe et la communauté se veut réussie.

32. Dans l'Épître 48, qui comporte plusieurs parallèles avec notre épître, il est par contre question de la cité des Frères. Voir Rasā̉il, t. IV, p. 171-173.

33. Spécialement Muqābasa 106. Voir Muqābasāt, éd. M. Tawfīq Ḥusayn. Bagdad, 1970, p. 449-465.

34. Ibn al-Nadīm signale encore un Kitāb al-șadī wa-l-ṣadāqa par Ibn al-Khammār (m. 942-943), un autre membre du cercle d'Ibn Sa'dān décrit par TAWHīīi dans l'Imtāc (voir Imtāá, II, p. 14 et 38, et KRAEMER, J., Humanism, p. 123-129). Voir Iвn AL-NADĪM, Fihrist, Maqāla 7, partie 1, éd. R. Tajaddod, Téhéran, 1971, p. 323.

35. Al-Hawāmil wa-l-Šawāmil, Le Caire, 1951, p. 131-133. Nous signalerons en note de la traduction les parallèles éclairants que l'on trouve dans ces textes.

36. Rasāill, t. IV, p. 45.

37. TAWḤī̄ī, Risālat al-Ṣadāqa wa-l-ṣadīq, éd. I. al-Kaylānī. Damas, 1964, p. 22. Le même style se retrouve encore notamment p. 15.

38. Tawhīdī, Muqābasāt, 106, p. 449, 1. 3-4 : al-hadd șaḥị walākin al-maḥdūd ġayr mawğūd. Voir aussi les passages de la Risālat al-șadāqa traduits par M. Bergé dans « Une anthologie sur l'amitié d'Abū Hayyān al-Tawhīīī », in Bulletin d'études orientales, XVI (1958-1960), p. 33 : « [...] avant tout, il convient d'être persuadé qu'il n'existe ni ami, ni ce qui ressemble à un ami » (Șadāqa, I. 6) ; «Il n'y a aucun profit à retirer de la fréquentation des hommes, aucun intérêt à s'en approcher, aucune confiance à mettre en eux, aucun secours à en attendre » (Șadāqa, I. 7). 
On peut voir dans cet épanouissement de l'éthique au $\mathrm{X}^{\mathrm{e}}$ siècle le fruit des traductions au siècle précédent des traités de l'Antiquité sur la question ${ }^{39}$. L'Éthique à Nicomaque d'Aristote est traduit par Ishāq b. Hunayn (m.910), accompagné de commentaires de l'Antiquité tardive. La République de Platon fournit une base aux réflexions touchant à l'organisation de la cité. Les textes de Galien véhiculent aussi une conception éthique propre ${ }^{40}$. Mais sans doute peut-on également chercher dans les conditions mêmes de l'activité des intellectuels à l'époque une autre cause pour l'intérêt pour le thème de l'amitié. Les mağlis décrits par les Frères dans notre épître comme lieu de réunion et d'enseignement n'étaient pas seulement le fait de mouvements plus ou moins secrets. Les penseurs, les lettrés et les savants avaient l'habitude de se réunir dans des cercles pour discuter les différents sujets de leurs sciences. De nombreux hommes de pouvoir et de nombreux savants avaient un cercle où se réunissaient différents hommes en leur domaine ${ }^{41}$. C'est donc semble-t-il naturellement que les penseurs ont repris et discuté le thème antique de l'amitié.

\section{HIÉRARCHIE DES FRÈRES ET THÉORIE DES ÂGES DE L'HOMME}

Un dernier passage de l'Épître 45 mérite encore particulièrement notre attention, celui où sont exposés les différents degrés d'accomplissement des âmes des Frères ${ }^{42}$. Ce passage important - à moins qu'il ne s'agisse de l'un de ses parallèles ${ }^{43}$ - se retrouve dans plusieurs textes postérieurs: il est cité dans l'article sur les Ihwān al-Ṣafā’ du Muntahab Șiwān alhikma ${ }^{44}$ et, dans la version de l'Épître 32, dans la version longue du Sirr al-asrār ${ }^{45}$.

L'idée de la hiérarchisation de la société humaine est bien ancrée dans les Rasāill, les Ihwān trouvant dans le Coran un fondement ou une confirmation de leur conception : « Le Très-Haut dit: "Nous en avons élevé certains au-dessus d'autres en degrés ${ }^{46}$." Il a fait en sorte que certains aient besoin des autres et que les uns soient corvéables par les autres. Ce propos montre clairement que le monde de l'homme est constitué de degrés, de classes et de cercles, les uns englobant les autres ${ }^{47}$. »

\footnotetext{
39. Sur le développement de l'éthique philosophique en islam, voir R. WALzER, art. «Akhlāq », in $E I^{2}$; G. HourANI, Reason and Tradition in Islamic Ethics, Cambridge, 1985 ; M. FAKHRY, Ethical Theories in Islam, Leyde, 1994 (2e éd.).

40. Voir R. Klibansky, The Continuity of the Platonic Tradition, Londres, 1939.

41. Voir M. Bergé, Pour un humanisme vécu, p. 52-60 et J. KRAemer, Humanism in the Renaissance of Islam, Leyde 1986, p. 54.

42. Rasā'il, t. IV, p. 57-58.

43. Ces parallèles se trouvent dans l'Épître 48 (Rasā'il, t. IV, p. 173-175), qui suit de près notre texte, et dans l'Épître 32 (Rasā̉il, t. III, p. 195-196), qui présente certaines différences.

44. Siğistānī, The Muntahab Șiwān al-ḥikma of Abū Sulaymān as-Siǧistānī, éd. D. M. Dunlop, La Haye, 1979, p. 161-163 (§ 310).

45. Sirr al-asrār, éd. 'A. Badawī, p. 131-132.

46. Voir Coran, 43:32, qui se lit : « Nous en avons élevé certains au-dessus d'autres en degré afin que les uns prennent les autres à leur service. »

47. Rasā'il, t. IV, p. 230.
} 


\section{Le quatre dans les Rasā'il}

Il n'est pas étonnant que ce soient ici quatre degrés qui soient distingués : l'Épitre 45 comprend en effet un certain nombre de séries par quatre. Il est y question non seulement des quatre sources du savoir (p. 42-43), des quatre demeures des gens eu égard aux deux grâces que sont les biens et la connaissance (p.52), mais aussi des quatre conditions à remplir pour arriver au plus haut rang pour l'homme (p.59), des quatre caractéristiques que se découvre celui qui atteint ce dernier niveau (p. 59), ainsi que des quatre demeures dans la foi (p. 60).

Le quatre est important dans l'ensemble des Rasā'il, mais sans exclusive (le chiffre 5 et d'autres sont également exploités ${ }^{48}$ ). Dans l'Épitresurlesnombres, les Ihwān nous apprennent que selon eux, si les nombres sont de quatre sortes (unité, dizaine, centaine et millier), ce n'est pas du fait de leur nature même, mais bien par un choix délibéré des savants qui ont voulu par là refléter ce qu'il en est des choses naturelles (saisons, éléments, directions...), elles-mêmes divisées en quatre par le Créateur comme reflet des choses spirituelles (Créateur, Intelligence universelle, Âme universelle, Matière première) ${ }^{49}$. L'Épitre sur la musique comprend également un passage relativement développé sur les tétrades voulues comme telles par le Créateur : partant de la division de l'année en quatre saisons, les Ihwwān énumèrent une série de phénomènes de la nature, de puissances de l'âme, d'actions, de caractères, etc. liés à chacune de ces saisons, formant ainsi un tableau quadripartite de la réalité du monde et des hommes ${ }^{50}$.

\section{Les puissances de l'âme et les fonctions des Frères}

Les quatre degrés des Frères sont définis à la fois par une fonction dans la communauté et par une puissance de l'âme propre à remplir celle-ci. Le premier degré est celui de la puissance d'intelliger ou puissance rationnelle (al-quwwa al-'âqila), arrivant à l'âge de quinze ans. Elle est définie comme celle qui « distingue les sensibles ${ }^{51}$ » et semble correspondre à l'âme humaine rationnelle (al-nātiqa al-insānīya) d'un autre passage ${ }^{52}$. Le deuxième degré est celui de la puissance de jugement, définie ailleurs comme «celle qui considère les significations des intelligibles ${ }^{53}$ ", qui arrive à l'âge de trente ans. Le troisième degré est celui de la puissance nomique ${ }^{54}$, arrivant à l'âge de quarante ans et qui est propre aux

48. À propos du chiffre 5, voir notamment Rasā'il, t. III, p. 380, où le 5 est décrit comme le chiffre de la religion de Muhammad, faisant référence entre autres aux cinq prières. Signalé par Y. MARQUET, La philosophie, p. 321.

49. Voir Rasā’il, t. I, p. 52-53, signalé par S. DiwaLd, Arabische Philosophie une Wissenschaft in der Enzyklopädie Kitāb Ihwān al-Ṣafā', Wiesbaden, 1975, p. 39.

50. Voir Rasā’il, t. I, p. 229-232 (trad. A. Shiloah, « L'Épître sur la musique, traduction annotée », in Revue des études islamiques, XXXIV (1966), p. 179-183).

51. Rasä'il, t. IV, p. 57.

52. Voir l'Épitre sur les caractères, t. I. p. 320.

53. Rasā'il, t. III, p. 195.

54. Ce qu'il faut comprendre par ce terme, apparu en arabe comme transcription du grec nomos, n'est pas toujours clair. Ici, l'on voit le terme utilisé pour caractériser une puissance associée à l'idée de commandement, d'autorité et de royauté. Dans le reste des Épitres, notamment dans l'intitulé de la quatrième partie, consacrée aux sciences "nomiques et légales (al-nāmūsìya wa-l-šar'ìya) », on voit que le terme nāmūs est utilisé conjointement avec le terme Šarîa pour indiquer ce qui concerne la religion, au sens de révélation, ou ce qui concerne l'au-delà, ou encore ce qui concerne la loi religieuse. Voir entre autres Rasāill, t. III, p. 191, où le nomos est distingué de la philosophie et de la 
rois, et le quatrième, celui de la puissance angélique (al-quwwa al-malakīya), qui arrive à cinquante ans et prépare à la séparation d'avec la matière. Sur cette puissance descend finalement la puissance d'ascension vers l'au-delà, du moins si l'âme s'est rendue parfaite avant de se séparer du corps ${ }^{55}$.

On le voit, chacun des degrés est caractérisé par une fonction qui correspond à ce qui est dit dans l'Épître 48 des habitants de la Cité des Frères ${ }^{56}:$ il y a d'abord les artisans, qui sont décrits dans l'Épître 48 comme «les maîtres des quatre éléments »; ensuite les chefs, ceux qui sont en charge de la conduite de la cité; puis les rois, qui possèdent le commandement et l'interdiction ; enfin, ceux qui dans l'Épitre 48 sont appelés « les divins qui possèdent le vouloir et la volonté ».

À chacun des degrés correspond une appellation particulière dans les Rasā'il ce qui peut fournir une clef de lecture intéressante de celles-ci : ceux qui sont au stade que domine la puissance rationnelle, les plus jeunes des adeptes de la communauté, sont appelés "nos frères pieux et miséricordieux » (Ihwānunā al-abrār wa-l-ruhamāà). Ceux du degré supérieur à celui-ci, chez qui domine la puissance de jugement, sont appelés "nos frères bons et nobles » (Ihwānnunā al-ahyār wa-l-fudalä'). Ceux qui occupent le troisième degré, celui des rois, sont appelés «nos frères nobles et généreux » (Ihwwānunā al-fuḍalā' al-kirām). Aucune appellation n'est associée à ceux qui occupent le degré le plus élevé, peut-être parce que les Rasāill ne s'adressent pas directement à eux ${ }^{57}$.

\section{Les âges de l'homme}

Comme chacun des degrés est liéà un âge, ce passage présente tout autant une hiérarchie qu'une division des âges de la vie humaine telle que la conçoivent les Ihwā̄n ${ }^{58}$. Bien qu'à première vue les Ihwān nous livrent ici une division quadripartite, à y regarder de plus prèscelle-ci cache en réalité une division de la vie en sept âges. En effet, si l'on rapproche ce passage d'autres extraits des Épitres où il est question des différentes puissances de l'âme et de l'âge de leur apparition, on voit que deux niveaux précèdent celui de l'âme rationnelle ici

médecine par le fait qu'il utilise des termes clairement liés à la révélation : «Les philosophes et les médecins l'appellent "nature de la génération et de la corruption", et le nomos l'appelle "ange d'entre les anges". Voir J. KRAEMER, "The Jihād of the Falāsifa », in Jerusalem Studies in Arabic and Islam, 10 (1987), n. 10 et n. 11, qui signale que šarỉa et $n \bar{a} m \bar{s}$ s ont tous deux été utilisés dans les traductions gréco-arabes pour rendre le terme grec nomos, dans tous les sens de celui-ci. Pour Kraemer, le terme šarīa, souvent qualifié de nāmūsīya, est utilisé par les Ihwwān comme visant aussi bien la loi prophétique que les lois philosophiques.

55. Voir Rasā’il, vol. III, p. 195-196 (Épître 32). Dans le cas contraire, l'âme reste sous la sphère de la lune, incapable de se séparer totalement de son corps. Voir notamment Rasā'il, t. I, p. 137 et t. II, p. 7.

56. Voir Rasā'il, t. IV, p. 172-173.

57. Rappelons que les Rasāil se présentent comme une propédeutique destinée à éveiller aux connaissances vraies. Voir ce qui en et dit dans l'inventaire édité en tête des Rasāill, où l'auteur des Rasā'il est dépeint comme un homme ayant un magnifique jardin, débordants de fruits, d'oiseaux merveilleux, de fleurs aux parfums délicieux, qui, voulant en faire profiter les autres, essuie un refus et est traité de fabulateur par ceux qu'il invite. Il se tient alors à la porte, et présente aux passants les plus beaux fruits de son jardin, éveillant ainsi en eux le désir d'en goûter davantage, mais sans les effrayer par trop de richesse (Rasā’il, t. I, p. 43-45).

58. Pour un aperçu général sur les différentes théories anciennes sur les âges de la vie, voir Fr. Boll, « Die Lebensalter » (1913), repris dans Kleine Schriften zue Sternkunde des Altertums, éd. V. Stegemann. Leipzig, 1950 ; E. SEARS, The Ages of Man. Mediaeval Interpretations of the Life Cycle, Princeton, 1986 ; J. A. Burrow, The Ages of Man. A Study in Medieval Writing and Thought, Oxford, 1986. 
présenté en premier lieu : avant quinze ans, il y a déjà quelque chose. Ensuite, la puissance angélique n'est pas la dernière puissance de l'âme. La puissance d'ascension, ici signalée en passant pour ne pas mettre à mal la division quadripartite, vient couronner l'existence humaine amenée son achèvement ${ }^{59}$.

Deux passages sont particulièrement intéressants à rapprocher de notre épître. Le premier est extrait d'une épître intitulée « Des principes des existants intellectuels selon l'opinion des Pythagoriciens ", l'Épître $32{ }^{60}$. Ce texte mentionne les deux puissances régissant l'homme avant quinze ans : d'abord la puissance animale, de la naissance à quatre ans, puis la puissance locutive, la faculté de parler, " qui exprime les noms des sensibles ». Il présente une différence importante par rapport à notre texte : il y a ici, en effet, une inversion entre puissance nomique et puissance angélique. Dans l'Épître 32, cette dernière puissance correspond au niveau atteint à l'âge de quarante ans révolus, et est ainsi liée au rang des rois. Dans ce contexte, il convient sans doute de lire plutôt quwwa malikiya, puissance royale, plutôt que quwwa malakiya, puissance angélique ${ }^{61}$.

Ce flottement autour de la puissance malakìya ou malikìya se retrouve dans d'autres passages des Rasāill, notamment dans l'Épittre des caractères. On trouve parfois dans ce dernier texte la même gradation que dans l'Épitre 45, de la puissance rationnelle à la puissance angélique, en passant par la puissance de sagesse ou de jugement et la puissance nomique ou législative ${ }^{62}$. Cela correspond fort bien à l'idée émise dans la même épître selon laquelle le but de l'âme rationnelle (nätiqa) est de devenir un ange en puissance, pour devenir un ange en acte quand se fera la séparation d'avec le corps ${ }^{63}$. Par contre, dans d'autres passages de cette épître, la puissance ou l'âme angélique/royale n'est plus attachée au niveau le plus élevé, mais bien au niveau caractérisé par la sagesse (hikma). Le niveau le plus élevé est alors décrit comme étant celui de l'âme sacrée (qudsīya), degré « des âmes prophétiques

59. Sur le chiffre sept et les divisions par sept, voir W.H. Roscher, Die Hebdomadenlehre des grieschischen Philosophen und Ärtze. Leipzig, 1906. Les Rasä’̉l comprennent aussi des divisions de la vie humaine en quatre âges : enfant (țfl), jeune (šäbb), homme (rağul), ascète (zāhid) « redevenant faible si la durée de sa vie ('umr) se prolonge » (Rasā'il, t. III, p. 504). Voir aussi Rasāill, t. I, p. 229-232, où les réalités de la nature sont divisées en quatre pour correspondre aux quatre saisons : l'enfance (șab̄a), dominée par la puissance imaginative (al-mutahayyila) est rattachée au printemps ; la jeunesse (šabāb), dominée par la puissance de réflexion (al-mutaffakira) est rattachée à l'été ; la vieillesse (kuhūla), dominée par la puissance de rétention (hâfiza), à l'automne ; aucun âge correspondant à l'hiver n'est mentionné - peut-être s'agit-il là d'un oubli dans le texte édité -, mais la puissance qui lui est propre, celle de remémoration (mudakkira) est, elle, précisée.

60. Le passage qui nous intéresse se trouve t. III, p. 195-196. Pour une analyse détaillée de cette épître, voir A. StRAface, « Testimonanzie pitagoriche alla luce di una filosofia profetica : la numerologia pitagorica negli Ihwān al-S'afā' », in Annali dell'Istituto Universitario Orientale di Napoli, 47 (1987), p. 225-241.

61. A. Straface traduit les différentes appellations des puissances de la façon suivante: «la forza loquente, raziocinante, sapienzale, di sovranità e legislativa » (A. STRAFACE, « Testimonanzie pitagoriche », p. 238).

62. Voir Rasā’il, t. I, p. 320. Voir aussi les hiérarchies p. 312-313 : âmes humaines, âmes des croyants (avec le verset correspondant dans l'Épître 45 au niveau de la puissance de sagesse ou de jugement), âmes prophétiques qui posent les nomoi divins (ou législations divines), âmes saintes et angéliques ; p. 329-330 : âmes végétatives, âmes animales, âmes rationnelles humaines, âmes intelligentes et de sagesse ou de jugement, âmes nomiques ou législatives, âmes angéliques.

63. Rasā’il, t. I, p. 378. 
qui posent les nomoi divins (ou législations divines) ${ }^{64} »$. Cela alors même que, quelques pages plus loin, l'âme sacrée est qualifiée de mlkīya (ici sans doute à comprendre au sens de « angélique »), ce qui lui est propre - la contemplation de la proximité de son seigneur étant mis en contraste avec ce qui est propre à l'âme douée de sagesse ou de jugement, - la contemplation des sciences et des connaissances ${ }^{65}$.

Un deuxième texte peut encore être utilement rapproché de ce que nous lisons dans l'Épître 45. Il s'agit du passage souvent mentionné dans les études sur les Ihwān où ceuxci exposent comment se fait selon eux le développement de l'homme sous l'influence des astres ${ }^{66}$. Il n'y est pas question des différentes puissances, mais bien des différents caractères et actes privilégiés suivant les âges, sous l'influence successive de chacun des sept astres du système ptolémaïque.

De la naissance à l'âge de quatre ans, c'est la Lune qui préside à la croissance, régissant le développement de l'enfant alors dominé par la puissance animale (p. 446).

Ensuite, et pour treize ans, c'est Mercure qui prend le relais, alors que la puissance locutive se manifeste, Mercure qui fait que dominent « la parole, le mouvement, les apprentissages, l'adab, le discernement et la compréhension» (p. 446).

Ensuite, pendant huit ans, c'est l'influence de Vénus qui se montre prépondérante. Celle-ci incite au désir des plaisirs charnels, pousse à fonder un foyer et à rassembler des biens (p. 447).

Durant les dix années qui suivent, l'homme vit sous l'influence du Soleil qui développe en lui les capacités liées à la puissance, la domination et l'organisation. L'homme s'occupe alors de l'éducation des enfants, s'inquiète de ce qui concerne ses proches. Il recherche également le pouvoir, l'élévation et les honneurs, « et ce sont là des caractéristiques, des mœurs et des actions dont ont besoin les rois et les chefs » (p. 447).

C'est Mars qui domine alors pour sept années. Il suscite «toutes les caractéristiques, les mœurs et les traits indispensables à ceux qui dirigent les affaires, commandent les armées, gardent les assemblées, régissent à la fois la royauté et le nomos » (p. 448).

Après cela, l'influence prédominante passe à Jupiter pour douze ans. Celui-ci pousse « à la religion et à la piété [...], au renoncement et à l'adoration, au retour vers Dieu ToutPuissant, par le jeûne et la prière, la charité et le pardon, la recherche et le désir de l'audelà » (p. 449).

Ensuite, « si l'homme fait effort et fait ce qui est décrit dans la šarïa [...] et agit selon ce qui est décrit dans la philosophie » (p.449), la prédominance passe à Saturne, qui incite

64. Voir Rasāil, t. I, p. 311-312 : on connaît cinq niveaux des quinze niveaux de l'âme, (1) âme végétative ; (2) âme animale ; (3) âme humaine ; (4) âme angélique ou royale (mlkiya), caractérisée par la sagesse, correspondant au verset coranique lié dans l'Épître 45 au deuxième niveau (celui de la puissance de jugement ou de sagesse) ; (5) l'âme sacrée, à laquelle sont liés la prophétie et le nomos.

65. Voir Rasā’il, t. I, p. 316.

66. Rasā’il, t. II, p. 446 et suiv. (Épître 25). Voir Y. MARQUET, La philosophie, p. 218-226, ainsi que « La détermination astrale de l'évolution selon les Frères de la Pureté », in Bulletin d'études orientales, XLIV (1992), p. 127-146 (cité désormais « Détermination »; C. BAfFionI, «L'influenza degli astri sul feto nell'enciclopedia degli Ihwān al-Ṣafā' », spécialement p. 432-438. 
« au repos, à la tranquillité et à l'inactivité, qui gèle les feux des passions du corps et fait s'en aller les puissances animales » (p. 449). Alors vient la mort naturelle.

Ce texte, qui fait penser à ce qu'on lit dans le Tétrabiblos de Ptolémée ${ }^{67}$, ne correspond pas entièrement avec ce que nous lisons dans les Épitres 32 et 45 . Ainsi les âges définis pour chacune des divisions ne sont-ils pas les mêmes. Par contre, l'on retrouve la même gradation dans le parcours de l'homme, de l'amour des choses corporelles au gouvernement, puis au désir de pouvoir et à la puissance, jusqu'à l'amour de l'au-delà et au désir du retour vers Dieu.

Les divers éléments présentés dans les Épittres 25, 32 et 45, peuvent être résumés sous forme de tableau de la façon suivante.

\begin{tabular}{|l|lll|l|}
\hline $0-4$ & puissance animale & & Lune & $0-4$ \\
$4-15$ & puissance locutive & & Mercure & $4-17$ \\
$15-30$ & puissance rationnelle & maitres-artisans & Vénus & $17-25$ \\
& & & Soleil & $25-35$ \\
$30-40$ & puissance de jugement & chefs & Mars & $35-42$ \\
$40-50$ & puissance nomique & rois & Jupiter & $42-54$ \\
$50-\ldots$ & puissance angélique & divins & Saturne & $54-\ldots$ \\
\hline
\end{tabular}

On le voit, un certain nombre de correspondances sont décelables, mais si les deux théories des âges ici présentées ne sont ainsi pas totalement incompatibles, elles ne sont pas non plus intégrées. Il faut sans doute voir là la marque de l'influence de sources diverses, sources qui ne sont pas toujours harmonisées, mais doivent-elles l'être pour les Ihwān?

\section{NOTRE TRADUCTION}

L'édition de Beyrouth étant la plus accessible, c'est elle qui a été préférée ici. Les variantes de l'édition du Caire seront signalées en notes. Les éditions plus récentes n'ont rien apporté de plus à ces éditions classiques.

Nous avons constaté que les p. 57-60 sont reprises à quelques points près aux p. 173177 du même volume, dans la septième épître des sciences nomiques et légales (Épître 48).

67. Tétrabiblos, IV, 10 (De la division des temps) :

0-4 Lune (promptitude de la croissance)

+10 Mercure (forme et façonne la partie raisonnable) = enfance

+8 Vénus (appétits désordonnés) = adolescence

+19 Soleil (autorité, désir de gloire et d'honneurs) = jeunesse

+15 Mars (force corporelle, désir d'actes mémorables) = homme

+12 Jupiter (conseil, répugnance pour travaux manuels, = vieillesse

Saturne (tristesse, colère, ennui, faiblesse corporelle) = dernière vieillesse

On retrouve une division des âges semblable dans le Kitāb al-Ğaninn écrit dans la seconde moitié du Xe siècle par 'Arīb b. Sa‘d (ou Sa‘îd) AL-QuRȚUBī (m. 979 ou 980), qui la qualifie de division des astronomes/logues, à distinguer de la division proposée par les médecins, en quatre parties. Voir Kitāb Halq al-ğanīn wa-tadbīr al-habāāā wa-l-mawlūdīn. Le livre de la génération du foetus et le traitement des femmes enceintes et des nouveaux-nés, publié, traduit et annoté par H. Jahier et A. Noureddine. Alger, 1956, p. 85-87. 
Nous indiquerons en notes les variantes du texte. D'autres parallèles peuvent encore être établis avec l'Épître 48, surtout à partir de la p. 165, parallèles dans les sujets traités cette fois, mais plus dans les termes eux-mêmes. C'est ainsi que les Ihwān y parlent aussi, par exemple, de l'entraide, de la nécessité de l'ouverture à toute science et toute doctrine, des quatre livres, etc. Les passages éclairants seront mentionnés dans les notes.

La numérotation indiquée en caractères gras entre crochets dans notre traduction renvoie à la pagination de l'édition de Beyrouth. Dans les notes, l'édition de Beyrouth est indiquée par le sigle $\mathbf{B}$, celle du Caire par le sigle $\mathbf{C}$. Le sigle $\mathbf{B}_{2}$ renvoie au t. IV, p. 173-177 de l'édition de Beyrouth dans le parallèle que nous venons de mentionner.

\section{TRADUCTION}

$[41,1]$ Quatrième épître des sciences nomiques ${ }^{68}$ et légales: Du comment des relations qu'entretiennent entre eux les Frères de la pureté, de leur entraide et de la sincérité de la sollicitude et de l'affection qu'ils ont les uns envers les autres pour ce qui est à la fois de la vie dernière ${ }^{69}$ et de la vie d'ici-bas. [5] (Épître XLV des Épîtres des Frères de la pureté)

Au nom de Dieu, Celui qui fait miséricorde, le Miséricordieux. Louange à Dieu et paix sur Ses serviteurs qu'Il a élus. Dieu est-Il meilleur ou ce que [les impies Lui] associent ? (27:59)

\section{[Prologue : Le cercle (mağlis) des Frères]}

Frère (que Dieu t'assiste ainsi que nous-mêmes par un esprit venant de Lui ${ }^{70}$ !), sache qu'il convient que nos frères (Dieu les assiste!), en quelque contrée qu'ils se trouvent, aient un cercle particulier où se réunir à des moments déterminés, où nul autre qu'eux ne pénétrera avec eux. Ils s'y entretiendront ${ }^{71}$ de leurs sciences et y discuteront de leurs secrets ${ }^{72}$. Leurs entretiens auront principalement pour sujet la science de l'âme, le sens et le sensible, l'intellect et l'intelligible, l'examen et l'étude des livres divins et des révélations prophétiques, et ce que signifie le contenu ${ }^{73}$ des prescriptions de la Loi. Ils s'y entretiendront aussi des quatre sciences mathématiques ${ }^{74},-$ je veux dire l'arithmétique, la

68. Sur ce qu'il convient d'entendre par le terme « nomique », voir plus haut, n. 54 .

69. Nous traduisons ainsi le terme dīn, qui nous paraît ici utilisé au même sens que dans l'expression yawm al-dīn, comme notamment dans le Kitāb al-Hudū $\bar{d}$ attribué à Ǧābir ibn Hayyān. Voir éd. P. Kraus, in Mukhtār Rasā'il Ǧābir ibn Hayyān. Le Caire, 1935, p. 108.

70. Voir Coran, 58:22: « Il a écrit dans leur cœur la foi et les a assistés par un esprit [venant] de Lui. »

71. Sur la mudākara comme conversation instructive et comme test de connaissance, voir G. MAKDISI, The Rise of Colleges. Édimbourg, 1981, p. 208-209.

72. Dans l'Épître 30, les Ihwān apportent encore d'autres éléments concernant ces mağlis. Il y est précisé qu'il en est de deux sortes, suivant le nombre des plaisirs : des mağlis pour le plaisir du corps et des mağlis pour celui de l'âme (voir Rasā’il, t III, p. 52). Al-Tawhīì̄ dans l'Imtāa présente cette même idée comme une citation de Platon : "Platon a dit: "Il est pour l'âme deux plaisirs, un plaisir qui est pour elle séparément de l'organisme, et un plaisir qu'elle partage avec l'organisme. Celui où l'âme est seule, c'est la science et la sagesse ; celui qu'elle partage avec le corps, c'est le manger et le boire, etc." » (AL-TAWHīDĪ, Imtā ', $17^{\mathrm{e}}$ nuit, éd. A. Amīn et A. al-Zayn. Le Caire, 1953, II, p. 36). Sur la division du bonheur en deux types suivant la division des plaisirs, voir aussi ici plus loin, p. [49].

73. Tadammana-hu : tadammana-hā BC.

74. Voir Rasā'il, t. I, p. 78-79 (Épître 2) : «Les [sciences] mathématiques sont de quatre sortes. La première est l'arithmétique, qui est la connaissance des nombres, de la quantité de leurs genres et de leurs propriétés, de leurs espèces et des propriétés de ces espèces. Cette science commence par le 1 qui est avant le 2. La deuxième, c'est 
géométrie, l'astronomie [15] et l'harmonie ${ }^{75}$. Ceci étant, leur souci le plus grand et leur but principal devra être l'étude des sciences divines, lesquelles constituent l'objectif ultime.

\section{[La quête nécessaire de toutes les sciences]}

Il convient que nos frères (que Dieule Très-Haut les assiste !) ne soient ennemis d'aucune $[42,1]$ science, ne fuient aucun livre et n'adoptent fanatiquement aucune doctrine ${ }^{76}$, car notre opinion et notre doctrine absorbent toutes les doctrines et réunissent l'ensemble des sciences. [Notre doctrine] consiste en effet à examiner selon la réalité l'ensemble des existants en leur totalité, sensibles et intelligibles, du premier au dernier, apparents et intérieurs ${ }^{77}$, manifestes et cachés, en tant qu'ils relèvent tous [5] d'un principe un, d'une cause une, d'un monde un et d'une âme une, qui en embrassent les différentes substances, les genres distincts, les espèces diverses et les différents individus.

\section{[Les quatre sources du savoir]}

Nous avons mentionné dans la deuxième épître ${ }^{78}$ que nos sciences sont tirées de quatre [espèces de] livres.

(1) Les livres composés par les sages et les philosophes en mathématique et en physique.

la géométrie (al-ğümațriyā), qui est la science de la géométrie (handasa) : c'est la connaissance des mesures et des distances, du nombre de leurs genres et des particularités de ces genres. Cette science commence par le point qui est l'extrémité de la ligne, c'est-à-dire sa fin. La troisième, c'est l'astronomie (asturunūmiyā), c'est-à-dire la science des étoiles ('ilm al-nuğūm) : c'est la science de la composition des sphères et des lignes du zodiaque, du nombre des astres, de leurs natures, de ce qu'ils indiquent pour les choses qui existent en ce monde, du fait du mouvement du soleil. Et la quatrième, c'est la musique, qui est la connaissance des harmonies et des rapports entre les choses différentes et les substances dont les puissances sont opposées. » Il est à remarquer que dans le texte de l'Épitre 2, ce sont les transcriptions des termes grecs qui sont utilisées pour désigner ces sciences, contrairement à ce qu'il en est dans notre passage.

75. Ta'lif: voir A. SHILOAH, «L'Épître sur la musique, traduction annotée », in Revue des études islamiques, t. XXXII (1964), p. 127, n. 2 : « Le terme ta'lif signifie littéralement "composition", mais comme [...] la "mesure" ou le nombre caractérise toute "composition", [..] on peut assigner au terme la notion d"'harmonie" dans son sens le plus large, laquelle est fondée sur l'idée de proportion.»

76. On retrouve les mêmes termes dans les Rasā’il, t. IV, p. 167 et suivantes. Pour les Ihwān, chaque doctrine est à considérer et à étudier, afin de pouvoir s'avancer sur le chemin menant à Dieu. Dans la Risālat al-Ğămi‘a, on peut lire dans le même sens : «Celui qui hait une des sciences véritables l'ignore ; et s'il l'ignore, il lui est hostile, la considère fausse, la rejette. Lorsque l'homme agit ainsi, il devient ennemi de la science, qui est ce qui lui est le plus propre et ce qui fait subsister son essence. Cela devient raison de déception et de perte, motif de perdition et de ruine. Il convient de ne rejeter aucune science car elles sont, nous l'avons dit, des nourritures pour l'âme [...]. Elles font vivre l'esprit, appellent à la noblesse et à la perfection, font atteindre les états les plus louables » (Ğâmi'a, t. II, p. 541). Il faut se mettre à l'écoute de toute science qui permet d'avancer vers le salut : « S'il possède une science que nous ne possédons pas, nous l'apprendrons de lui, comme les jeunes gens apprennent des scribes, nous l'écouterons comme écoutent ceux qui prêtent l'oreille au sermon de celui qui prêche le vendredi. Si ce qu'il dit est vrai, nous le suivrons comme celui qui est derrière lui (ma'mūn) suit l'imām, et s'il désire ce que nous avons comme science, nous lui enseignerons à la mesure de son désir et de sa quête » (Rasā'il, t. IV, p. 167).

77. Bāțin wa-zāhir : voir entre autres Rasā'il, t. I, p. 328 : « Sache-le, pour toutes les choses qui existent en ce monde, il y a une apparence, et une [réalité] intérieure. Les apparences des choses sont des enveloppes et des os, tandis que leurs [réalités] intérieures sont pulpe et moelle. »

78. Nous n'avons pas trouvé dans la deuxième épître une telle référence. Mention est faite de ces quatre espèces de livres dans l'Épître 48 (Rasā’ll, t. IV, p. 167-168), septième de la quatrième partie. 
(2) Les livres révélés qu'ont apportés les prophètes (sur eux les bénédictions de Dieu !), comme [5] la Torah, l'Évangile, le Furqān ${ }^{79}$, et les autres pages des prophètes dont les significations proviennent des anges par révélation, ainsi que ce qui s'y trouve comme secrets cachés.

(3) Les livres naturels, qui sont les formes des figures des existants telles qu'elles sont maintenant ${ }^{80}$ : la façon dont les sphères [célestes] sont disposées les unes par rapport aux autres ${ }^{81}$, les divisions du zodiaque, les mouvements des astres et les mesures de leurs masses, les changements dus au temps, la transmutation des éléments, les différentes sortes de ce qui s'engendre comme minéraux, animaux et végétaux, et les [divers] types [15] de produits faits de la main de l'homme. Tout cela, ce sont des images, des métaphores, qui indiquent des significations subtiles et des secrets délicats, dont les gens voient l'apparence sans en connaître la signification profonde, qui est une description subtile du Créateur- qu'Il soit loué !

(4) La quatrième espèce enfin, ce sont les livres divins que ne touchent que les purifiés ${ }^{82}$, les anges, et qui sont dans les mains de scribes généreux et pieux ${ }^{83}$. Ce sont les substances des âmes, leurs genres, leurs espèces et leurs individus, le fait qu'elles utilisent les corps, les mettent en mouvement et les régissent, [20] qu'elles ont autorité sur eux et manifestent leurs actions grâce et à partir d'eux, état après état, alors que passent le temps et les moments des conjonctions et des révolutions; le fait que tantôt certaines tombent dans l'abysse des corps, tantôt certaines s'élèvent [hors] des ténèbres de la carcasse [corporelle]; qu'elles sortent ${ }^{84}$ du sommeil de la négligence et de l'oubli, $\left[\mathbf{4 3 , 1}\right.$ ] qu'elles se rassemblent ${ }^{85}$ pour le Compte et la Balance, qu'elles passent sur la Voie et arrivent aux Jardins, ou qu'elles soient détenues dans les gouffres de l'enfer et des feux, ou [encore] qu'elles séjournent dans l'entre-deux (barzah) ou se tiennent sur les redans (a'rāf), ainsi que Dieu, le TrèsHaut, l'évoque en disant: "Derrière eux est un entre-deux jusqu'au jour où ils seront ressuscités ${ }^{86}$ ». Le Béni et Très-Haut dit également: "Sur les redans sont des hommes qui les reconnaissent [5] chacun par leurs traits distinctifs ${ }^{87}$. $\gg$ Ce sont les hommes qui

79. Un des façons de désigner le Coran. Voir R. PARET, art. « Furqān », in EI $I^{2}$ t. II, p. 971-972.

80. Ce sont là les livres que « les gens voient mais ne sont pas aptes à lire » (Rasā’ il, t. IV, p. 167).

81. Nous traduisons ainsi le terme «tarkỉb», qui indique certes la composition, mais aussi le rapport du tout à ses parties, l'arrangement, l'ajustement d'une chose à une autre, l'emboîtement. Voir A. DE BiBERSTEIN-KAZIMIRSKI, Dictionnaire arabe-français. Paris, 1860, s.v. et E. W. LANE, Arabic-English Lexicon. Cambridge, 1984 (rééd.), s.v.

82. Coran 56:77-79: « Voici un noble Coran, en un livre caché, que ne touchent que les purifiés. »

83. Coran 80:15. Ces livres, « les autres ne les partagent pas avec nous et personne ne les comprends à part nous » (Rasā'il, t. IV, p. 167).

84. Inbi ${ }^{a} a t$, terme utilisé aussi dans le sens de « ressusciter ».

85. Voir Coran 19:85: «Le jour où Nous rassemblerons les pieux pour aller par groupes vers le Miséricordieux. »

86. Coran 23:100. Voici comment Tabarī commente ce terme: «Derrière eux est une barrière qui fait obstacle entre eux et le retour, c'est-à-dire jusqu'au jour où ils ressusciteront de leurs tombes. [...] C'est un voile entre la mort et le retour au monde d'ici-bas, [...] ce qui est entre ce monde-ci et la vie dernière, [...] ce qui est entre la mort et la résurrection » (Tafsìr, éd. Le Caire, al-Halabī, 1968, 18 partie, p. 52-53). Les Ihwwān parlent parfois de l'entre-deux comme d'un lieu de passage avant d'aller dans le Jardin ou le Feu. Voir notamment Rasā'il, t. I, p. 329.

87. Coran 7:46. Différentes interprétations de ce qu'il convient de comprendre par ces "hommes des redans" coexistent. Voir R. PARET, art. «al-A'rāf », in $E^{2}$; L. GARDET, Dieu et la destinée de l'homme, Paris, Vrin, 1967, p. 332-334. On 
se trouvent dans des maisons que Dieu a permis d'élever et dans lesquelles Son Nom est rappelé. Ni commerce ni vente ne les distraient du rappel de Dieu ${ }^{88}$. Tel est l'état de nos frères nobles et généreux ${ }^{89}$. Prenez-les donc pour modèles, ô frères, et vous serez comme eux! Nous avons exposé dans nos Épîtres tout ce dont nos frères ont besoin [provenant] de ceux qui s'adonnent à ces sciences.

SECTION : [DE L'AMITIÉ ET DU CHOIX DES AMIS $]^{90}$

[La diversité des hommes]

[10] Lorsque l'un d'entre eux veut adopter un nouvel ami ou un frère nouveau, il convient à nos frères (que Dieu les assiste !), en quelque contrée qu'ils se trouvent, de considérer la situation de celui-ci, de se renseigner à son sujet, de sonder son caractère et de l'interroger sur sa doctrine et sa croyance, afin de savoir s'il est apte ou non à l'amitié, à la pure affection et à la véritable fraternité. Parmi les gens en effet, il y a des groupes dont les natures rivalisent et sortent de l'équilibre, dont les habitudes sont mauvaises et corruptrices, et dont les doctrines sont divergentes et [15] déviantes. Il en est des bons et des méchants, des ingrats et des reconnaissants, des hommes de confiance et des fourbes, des doux et des impudents, des généreux et des avares, des courageux et des lâches, des envieux et des affectueux, des libertins et des chastes, des anxieux et des patients, des avides et des sobres, des dociles et des rétifs, des gens rudes et durs et des gens subtils et fins, des gens intelligents et des gens stupides, des savants et des ignorants, des gens aimants et des gens haineux, des gens conciliants et des gens contraires, des hypocrites et des sincères, des gens de bon conseil et des perfides, des orgueilleux et des humbles, [20] des ennemis et des amis, des croyants et des mécréants ${ }^{91}$, de ceux qui reconnaissent et

peut résumer les grandes lignes de ce qu'en dit Țabarī de la façon suivante : le terme lui-même peut se comprendre de deux façons : comme un "mur ayant une crête comme la crête d'un coq », un « mont entre le Jardin et le Feu ", ou bien, en rapprochant le terme de la racine ' $\mathrm{R} F$ au sens de "connaître", comme lieu où se tiennent ceux qui « connaissent les gens ». Pour ce qui est de l'identité de ceux-ci, Tabarī rapporte différentes interprétations : (1) ce sont les gens dont les bienfaits égalent les méfaits, - « ils sont mis là jusqu'à ce que Dieu juge à leur sujet » - ; (2) ce sont des gens qui ont été tués sur le chemin de Dieu, c'est-à-dire en martyrs, mais en désobéissant à leur père ; (3) c'est un groupe de vertueux maîtres du figh et savants ; ou encore, des anges et pas des fils d'Adam, « qui connaissent les deux groupes à la fois, les gens du Feu et les gens du Jardin, et cela avant que les gens du Jardin n'entrent dans le Jardin ». Cette dernière interprétation est immédiatement rejetée par Țabarī comme n'ayant ni tradition du Prophète ni consensus de la communauté comme appui. L'interprétation des Ihwān semble être la troisième évoquée par Țabarī: les A'rāf sont pour eux un lieu d'honneur. Voir également Rasā’̉l, t. II, p. 430, 1. 20-21: « Tu seras alors sur les montagnes d'al-A'rāf avec les prophètes, les véridiques, les témoins et les vertueux », ainsi que t. II, p. 140, 1. 9-12: «Les gens des A'rāf, qui sont les gens qui ont la connaissance ». Voir à ce propos Y. MARquet, La philosophie, p. 390.

88. Voir Coran, 24:36-37 : «Dans des maisons que Dieu a permis d'élever et dans lesquelles Son Nom est rappelé, dans lesquelles Le glorifient à l'aube et au crépuscule des hommes que ni commerce ni vente ne distraient du rappel de Dieu, de l'accomplissement de la prière, de l'acquittement de l'aumône, et qui redoutent un jour où les cœurs et les regards seront retournés. »

89. Dans la hiérarchie des Frères décrite plus loin dans cette épître, cette épithète est réservée aux Frères du troisième niveau. Voir plus bas, p. [57].

90. Sur le choix des amis, comparer MısкаwaYh, Traité d'éthique (Taḍhīb al-ahlāq wa-tațhìr al-a'rāq), traduction M. Arkoun. Damas, 1969, p. 242-245.

91. Zindīq : le mot a dès l'origine deux sens. Il désigne tout d'abord ceux qui adhèrent au manichéisme, mais aussi, en un sens plus large, tout mécréant. «Ce sont les dualistes qui sont les zanādiqa, mais on y ajouta tous ceux qui pro- 
de ceux qui nient, des gens qui vont vers l'avant et des gens qui retournent en arrière, et autres caractères semblables, louables et blâmables, opposés les uns aux autres. Sache-le, le pire de tous ces groupes, ce sont ceux qui ne croient pas au Jour du Compte, et le pire $[\mathbf{4 4 , 1}]$ des caractères, c'est l'orgueil d'Iblis, l'ambition d'Adam et la jalousie de Caïn ${ }^{92}$. Ce sont là les mères des désobéissances ${ }^{93}$.

Sache-le, les caractères imprimés naturellement dans les gens sont fonction des différentes compositions de la complexion de leurs organismes, fonction aussi des différentes configurations de la sphère au fondement de leur naissance ${ }^{94}$. Nous avons exposé cela plus amplement dans l'Épittre des caractères ${ }^{95}$.

[5] Sache-le, il est des gens dans lesquels sont imprimés un seul et même caractère ou nombre de caractères louables et blâmables. Les habitudes mauvaises renforcent les caractères mauvais, tandis que les belles habitudes renforcent les caractères louables ${ }^{96}$. Il en va de même des opinions et des croyances. Il est en effet des gens qui pensent et croient, dans leur religion et dans leur doctrine, qu'il leur est licite de verser le sang de quiconque s'oppose doctrinalement à eux ${ }^{97}$, comme les juifs ${ }^{98}$, les hāāiŏites ${ }^{99}$ et tous les mécréants.

[10] Il est aussi des gens dont les opinions et la croyance, dans leur religion et leur doctrine, sont la compassion et la sollicitude envers tous les gens, qui ont pitié des pécheurs et demandent pardon pour eux, qui ont de l'affection envers tout vivant doué d'esprit et

fessaient l'éternité du monde et niaient qu'il soit venu à l'existence » (MAs'ūīi, Murūğal-dahab, éd. Ch. Pellat. Beyrouth, 1966, t. I, p. 291 ; traduit par G. MonNot in Penseurs musulmans et religions iraniennes. 'Ábd al-Ğabbār et ses devanciers. Paris, 1974, p. 309). On trouvera chez Mas'ūdī l'étymologie du terme. Voir F. C. DE BLoIs, art. « zindīk », in $E I^{2}$.

92. La jalousie est pour les Ihwwān la racine de la haine. Ainsi écrivent-ils : «Sache que le fondement de la haine dans ce monde-ci et dans l'autre monde, c'est la jalousie. [...] La jalousie ruine les demeures, produit les dissensions et engendre la haine, la rancœur, la rage, l'offense, l'injustice et l'oppression, et ce qui y ressemble. C'est également l'une des plus grandes raisons de la divergence des vues et des croyances » (Rasā'il, t. III, p. 166).

93. ummahāt al-ma‘āșī : voir Lisān al-‘Arab, sous umm (vol. 12, p. 31, col. 2, 1. 4) : «La mère de toute chose : son fondement et sa base. " Ces trois vices fondamentaux sont également évoqués dans l'Épître sur les caractères, qui énumère une série de leurs «sœurs et ramifications". Voir Rasā’il, t. I, p. 350-351. Il y a toute une littérature sur les «mères des vices » dans la tradition chrétienne, avec pour point de départ l'orgueil (voir Ecclésiaste, X, 15), la cupidité (I Tim., VI, 10), etc. Voir Dictionnaire de théologie catholique, Paris, 1923-1950, sous « orgueil », « envie », et «péchés».

94. Voir Y. MARQUET, « Détermination astrale », p. 143 : « Lors de la naissance, il y a à l'horizon Est du lieu, un degré ascendant, régi par une planète. Ce degré et cette planète seront le "significateur" de l'enfant. »

95. Épître 9, Rasā’il, t. I, p. 296-389.

96. Le caractère, c'est ce qui pousse à agir « sans qu'il y ait pensée ni réflexion » (Rasā'il, t. I, p. 305). MisKAWAYH utilise les mêmes termes. Voir Traité d'éthique, p. 51.

97. Voir le dialogue du damné et du sauvé dans l'Épître de la résurrection, Rasāil, t. III, p. 312 (trad. J. R. Michot, in Bulletin de philosophie médiévale, 16-17 (1974-1975), p. 137-138), où le damné croit licite de verser le sang de tout homme qui s'oppose à lui doctrinalement, fût-il d'entre les musulmans (" de ceux qui professent "Il n'est pas de dieu sinon Dieu"»).

98. Voir l'histoire du juif et du Mage relatée dans l'Épître sur les caractères (Rasā'il, t. I, p. 308), où le juif déclare que sont licites pour lui le sang et les biens de tout qui lui est opposé dans sa religion et sa doctrine. Sur les sources et le devenir de ce récit, voir J. L. KRAemer, Humanism, p. 80-81.

99. Voir G. Levi Della VIDA, art. « Khāridjites », in EI², spécialement p. 1108 ; Ch. Pellat, art. « Isti'rāḍ », ibid., qui traite de ce terme technique des hāariğites, en particulier des Azāriqa, qui désignait « le meurtre religieux, la mise à mort [...] des Musulmans et des païens réfractaires à leur doctrine ». Voir aussi W. M. WATt, The Formative Period of Islamic Thought. Oxford, 1998 (1 $1^{\text {re }}$ éd. Édimbourg, 1973), p. 22. Pour une étude récente sur la question, remettant en cause certaines analyses antérieures, voir P. CRONE et Fr. Zimmermann (éd.), The Epistle of Sālim ibn Dhakwān, Oxford, 2001, Appendix 4: isti'rāḍ, p. 325-329. 
veulent le bien-être de tous. Telle est la doctrine des pieux, des ascètes, des vertueux parmi les croyants, et telle est également la doctrine de nos frères généreux ${ }^{100}$.

\section{SECTION: [L'AMI SINCÈRE]}

[15] Lorsque tu veux adopter un ami ou un frère, il convient que tu l'examines comme tu examines les dirhams et les dinars, les terrains dont le sol est bon pour les semailles et pour les plantations, et comme les fils de ce monde examinent la question du mariage, l'achat des esclaves et les marchandises qu'ils achètent.

Quand il s'agit d'adopter des frères, sache-le, le risque encouru est plus important et plus grave encore qu'en toutes ces choses, parce que ce sont les frères sincères qui apportent leur aide dans les affaires de l'autre monde et de ce monde-ci. Ils sont plus précieux [20] que le souffre rouge ${ }^{101}$ ! Lorsque tu en as trouvé un, attache-toi donc à lui : il sera [pour toi] la fraîcheur de l'œil ${ }^{102}$, la félicité du monde d'ici-bas, le bonheur dans l'au-delà.

Les frères sincères sont en effet des auxiliaires pour repousser les ennemis, un ornement auprès des amis, des piliers sur lesquels s'appuyer en cas de coup dur et d'affliction, $[\mathbf{4 5 , 1}]$ un support sur lequel s'adosser en cas d'adversité, dans les bons et les mauvais moments ${ }^{103}$. Ils sont un trésor conservé pour le jour de besoin, une aile [protectrice] qui s'abaisse en cas de préoccupation, une échelle pour s'élever vers les hauteurs, un accès auprès des cœurs lorsqu'on recherche une intercession, une forteresse inexpugnable vers laquelle se réfugier aux jours d'effroi et de terreur. Si tu es absent, ils te protègent ; si tu dépéris, ils te soutiennent; et s'ils te voient un ennemi, ils le matent ${ }^{104}$. [5] Un seul d'entre eux est comme l'arbre béni ${ }^{105}$ dont les branches s'offrent à toi chargées de fruits, dont les feuilles au parfum excellent t'ombragent et te protègent de leur belle ombre. Si tu te rappelles, il

100. Dans la hiérarchie des Frères décrites plus bas, cette épithète désigne les Frères qui occupent le troisième degré. Voir p. [57].

101. Le proverbe a'azz min al-kibrit al-ahmar est mentionné par G. FREYTAG, Arabum Proverbia, Onasbrück, 1968 ( $1^{\text {re }}$ éd. 1838-1840), ch. XVIII, 220. Le soufre rouge serait une substance très rare, considérée souvent comme légendaire, substance qui « entre dans la fabrication de l'or » (QAzwīnī, Kitāb 'Ağă’’ib al-mahlūqāt, éd. F. Wüstenfeld, Göttingen, 1848-1849, vol. II, p. 52, l. 12 et suiv.). Selon al-Maqqarī, il s'agirait de l'or rouge (cité par N. Tomiche, dans son édition de Iвn ḤAzм, Épître morale (Kitāb al-ahlāq wa-l-siyār), Beyrouth, 1961, p. 74, n. 3). L'on retrouve chez ARISTOTE la même insistance sur la rareté des véritables amitiés, par exemple dans Éthique à Nicomaque, 1156b24-25. Voir également Miskawayh, Traité d'éthique, p. 239-240.

102. Expression coranique qui exprime l'idée de joie, de consolation. Kazimirski rend cette expression de la façon suivante : «Ce qui réjouit l'œil, comme larme froide, qui est la larme de joie. métaph., enfant [...], fils qui est pour son père un sujet de consolation » (KazImIRsKI, Dictionnaire arabe-français, s.v.). Voir par exemple Coran 25:74 : «Ceux qui disent : "Notre seigneur, accorde-nous la fraîcheur des yeux en nos épouses et notre descendance." »

103. Une expression similaire, attribuée à Šabīb b. Shayba (Basrā et Bagdad, m. vers 770-780), se retrouve chez TAWHīDĪ, Risālat al-șadāqa wa-l-șadīq, éd. I. Kaylānī, p. 36, ainsi que chez IBN 'ABD RABBIH (m. 328/940), al-'Iqd al-farīd. Le Caire, 1940-1953, vol. II, p. 304, 1. 6: "Shabīb b. Šayba a dit : "Les frères sincères (Ihwān al-șafä') sont la meilleure des acquisitions de ce monde-ci. Ce sont des agréments dans l'aisance, des aides dans l'affliction, des auxiliaires contre les ennemis." »

104. Ainsi que nous l'avons signalé dans notre présentation, le style rappelle ici celui de différents passages de la Risālat al-șadāqa wa-l-ṣadīq de Tawhīì̄. Voir plus haut, p. 320, et n. 37.

105. Terme coranique, voir Coran 24:35. Il s'agit de l'arbre dont est extrait le combustible de la lampe de la Niche des Lumières : « Dieu est la lumière des cieux et de la terre. Sa lumière est semblable à une niche où est une lampe. [...] Elle est allumée grâce à un arbre béni, un olivier ni oriental ni occidental dont l'huile semble éclairer sans même que le feu la touche.» 
t'aide, et si tu oublies, il te fait te rappeler. Il t'exhorte à la piété et te précède vers elle ; il te fait désirer le bien, te devance vers lui et te guide vers lui. Il dépense et son bien et luimême à ton profit.

Si Dieu te gratifie, mon frère, de quelqu'un dont tel est l'attribut, dépense pour lui et toi-même et ton bien ${ }^{106}$ ! Préserve son honneur avec le tien, étends ton aile à son profit, confie-lui ton secret, consulte-le concernant tes affaires ${ }^{107}$, soigne ton œil en le regardant ! Lorsqu'il est absent, fais-toi une habitude de te souvenir de lui et de penser à lui. S'il commet une erreur, pardonne-lui. S'il fait un faux-pas, minimise la chose auprès de lui. Ne le laisse pas dans la solitude : il craindrait ta rancœur ${ }^{108}$. Rappelle-toi ses bienfaits passés lorsqu'il agit mal, pour qu'il soit en confiance et se sente à l'abri d'un danger de ta part. Voilà le meilleur moyen de préserver son affection et de prolonger sa fraternité.

\section{[15] SECTION : [LES AMITIÉS IMPOSSIBLES]}

Sache-le, mon frère, il est des gens qui ne sont pas du tout aptes à l'amitié, à la fraternité ou à la proximité. Examine donc celui dont tu te fais le compagnon et que tu fréquentes, et ne te laisse pas duper par l'apparence des choses sans en connaître le fond, ni par la douceur de l'immédiat avant d'examiner l'amertume de ce à quoi il aboutit.

Lorsque tu veux adopter un frère ou un ami, considère d'abord sa situation, éprouve son caractère, interroge-le [20] sur sa doctrine et sa croyance, examine ses habitudes, son naturel, ses qualités et ses mouvements. Au physiognomoniste, le fond des choses n'est pas caché lorsqu'il en examine les apparences.

Sache-le, parmi les gens, il en est qui prennent l'allure de l'ami, te trompent [46,1] en faisant semblant d'être d'accord avec toi et en simulant de l'amour envers toi, alors que c'est son contraire qui est dans leur poitrine et leur for intérieur. Ne te laisse donc pas duper et ${ }^{109}$ fais-toi une certitude.

Sache-le, les actions des gens telles qu'elles apparaissent sont fonction des caractères les marquant naturellement, fonction aussi des habitudes avec lesquelles ils ont grandi, ou fonction des opinions auxquelles ils croient. [5] Parfois, on voit l'homme être vaniteux et fanfaron, ou acariâtre et entêté, rude et dur, querelleur et disputeur, envieux et haineux, hypocrite et ostentateur, avare et ladre, lâche et vil, rusé et perfide, orgueilleux et sans pitié, vorace et avide. [On en voit aussi] qui aiment l'éloge et la louange plus qu'ils ne le méritent, humilient leurs pareils, méprisent leurs proches et les gens, les blâmant ou se fiant en leur propre force et en leur propre puissance. Ces gens, sache-le, [10] ne sont aptes ni à l'amitié

106. TAWH̄ī̄I utilise une expression similaire. Voir Risālat al-ṣadāqa wa-l-ṣadīq, p. 37.

107. Voir Coran 3:159: « Pardonne-leur et demande pardon pour eux, consulte-les en affaire. » Sur le même sujet, al-Ǧāhiz (m. 868 ou 9) écrit : «Que l'homme que tu distingueras le soit parce qu'il le mérite, pour la sincérité de son affection, le désintéressement de son conseil, après que tu auras éprouvé son caractère et ses qualités et parce que tu es convaincu, pour l'avoir expérimenté toi-même, qu'il sait que son salut est lié au tien comme sa perte dépend de la tienne. Alors, remets-t'en à lui, fais-le participer à tes affaires les plus personnelles et à tes secrets les plus cachés » (Risālat al-ma'ā̌s wa-l-ma'ād, trad. Ch. Vial, in AL-ǦĀHIZ, Quatre essais, vol. 1. Le Caire, 1976, p. 46).

108. ARISTOTE écrit à ce propos : «L'éloignement, en effet, sans interrompre absolument l'amitié, en suspend la manifestation (l'acte, energeia). Et l'absence se prolongeant, c'est l'amitié elle-même qui [...] s'ensevelit dans l'oubli, aussi dit-on : "Bien des amitiés, faute de pouvoir se parler, ont péri” » (Éthique à Nicomaque, 1157b10-13).

109. Wa- : aw BC. 
ni à la fraternité la plus pure, car ces caractères, opinions et habitudes corrompent ce qu'ils croient de leurs frères. En effet, celui qui choisit d'exiger ce qui ne lui est pas nécessaire, ne se permet pas à lui-même de dépenser ce qui est nécessaire ${ }^{110}$.

Ainsi leurs caractères empêchent-ils l'envieux, l'entêté et le colérique de se soumettre au réel ${ }^{111}$. L'entêtement et l'orgueil empêchent de même de mettre fin à une controverse et à un différend. Ainsi aussi la rudesse et la dureté empêchent-elles la familiarité et le confort, [15] tandis que la hargne et la colère excitent à l'arrogance. Bref, tous ces caractères détruisent l'affection, vont à l'encontre de la fraternité la meilleure, pèsent aux âmes ; elles sont dévastatrices pour l'intimité et la tranquillité, font fuir la sociabilité naturelle, ternissent l'existence et rendent la vie détestable.

L'amitié ne peut être accomplie, sache-le, entre deux [personnes] de natures différentes, parce que les contraires ne se réunissent pas. Le généreux et l'avare en fournissent l'exemple. Ils sont en effet contraires par nature et, entre les deux, il n'y aura pas d'amitié accomplie, [20] l'affection ne sera pas pure, l'existence ne les comblera pas. En effet, lorsque le généreux fait quelque chose - dépense ou libéralité - que sa générosité lui impose, l'avare voit en lui un prodigue qui aurait fait ce qui ne convient pas et n'est pas permis. Lorsque l'avare, par contre, fait par nature quelque économie que son avarice lui impose, le généreux voit en lui quelqu'un qui a commis une abomination et dont l'action n'est pas bonne. Cela devient donc pour chacun une raison de faire des reproches à son compagnon. Ainsi l'avare croit-il qu'il y a chez le généreux $[\mathbf{4 7 , 1}]$ bêtise, gaspillage des biens et omission de l'examen des conséquences [de son action], tandis que le généreux croit qu'il y a chez l'avare dépravation, bassesse, petitesse d'âme et étroitesse dans le dessein. Lorsque ceci se produit entre eux et persiste, cela devient de la rudesse, laquelle perdure, si bien qu'elle devient de l'inimitié, celle-ci devenant à son tour de la dureté. Il en va de manière analogue de toute paire de caractères différents, contraires l'un à l'autre : ils rendent nécessaire la dispute, la dispute [5] rend nécessaire la rivalité, la rivalité produit la fureur, la fureur implique la haine, et la haine est le contraire de l'amitié ${ }^{112}$.

\section{SECTION : [LA CONSERVATION DE L'AMI ${ }^{113}$ ]}

Sache-le, adopter des amis et des frères, c'est comme acquérir des biens et des provisions. Parmi les gens, il en est en effet qui consument leur vie à chercher un ami en accord [avec eux] et ne trouvent pas; [10] ils sont semblables à celui qui consume sa vie à chercher à réunir des biens et n'y parvient pas. Il en est aussi auxquels une abondance de biens est octroyée. D'autres enfin sont bons pour ce qui est d'acquérir les biens mais pas pour ce qui est de les conserver. Il en va de même pour ce qui est d'adopter des frères et des

110. Nous ne sommes pas certaine du sens de cette proposition.

111. Voir Rasā’il, t. I, p. 351 (Épître sur les caractères) : «Parmi les sœurs de l'orgueil, il y a de refuser de se soumettre au réel », et p. 352 : «Celui qui est trop orgueilleux pour se soumettre au réel est ennemi de l'obéissance. Or on a dit que l'obéissance est le nom de Dieu le plus grand, par lequel subsistent les cieux et la terre selon la justice. Le contraire de l'orgueil, c'est accepter le réel et s'y soumettre ».

112. On retrouve de telles chaînes (de vices mais aussi de biens) dans la version longue du Sirr al-asrār. Voir notamment éd. 'A. Badawī, p. 75-76.

113. Sur la conservation de l'ami, voir Miskawayh, Traité d'éthique, p. 246-253. 
amis : d'aucuns ne sont pas capables de les conserver et d'avoir des égards envers eux. Ils en viennent donc à l'inimitié après l'amitié, et à la haine après l'affection.

[15] Après avoir adopté un ami, il convient que ce à quoi tu t'appliques le plus et ce dont tu te soucies le plus, ce soit de le conserver ${ }^{114}$, d'avoir des égards envers lui et d'accomplir ce qu'il est en droit d'attendre de toi, de sorte que l'amitié ne devienne pas inimitié après un long compagnonnage, par lassitude ou ennui, ou par des doutes, des présomptions, des suspicions s'introduisant dans l'affection, ou du fait de calomnie et de diffamation provenant de quelqu'un qui serait opposé à votre relation et s'efforcerait de la détruire. Approfondis ce domaine, mon frère, et ne le néglige pas !

[20] Sache-le, mon frère, l'homme subit de nombreuses colorations et connaît peu de stabilité en un seul et même état. Ainsi passe-t-il de la richesse à l'indigence ou de l'indigence à la richesse, de la sédentarité au voyage, du célibat ${ }^{115}[\mathbf{4 8 , 1}]$ au mariage, de l'assujettissement au pouvoir, de l'oisiveté à l'occupation, de l'adversité à la félicité, de l'élévation à l'humilité, de l'humilité à l'élévation, de l'artisanat au commerce, de la compagnie d'un groupe à la compagnie d'autres [gens], des conceptions d'une doctrine à une [autre] doctrine, de la jeunesse à la vieillesse, de la santé à la maladie. Peu nombreux sont les gens à qui adviennent l'un ou l'autre de ces états ou l'une ou l'autre de ces affaires d'ici-bas sans que leur adviennent aussi [5] de nouvelles mœurs et un autre caractère, sans que leurs mœurs ne varient avec leurs frères et ne se colorent avec leurs amis. Ceci à l'exception des Frères de la Pureté ${ }^{116}$ dont l'amitié n'est pas extérieure à l'essence. Toute amitié qui est due à quelque raison cesse lorsque cette raison disparaît, mais il n'en va pas ainsi de l'amitié des Frères de la Pureté : leur amitié est une proximité de parenté, et leur parenté consiste à vivre l'un pour l'autre et à hériter l'un de l'autre. Cela parce qu'ils pensent et croient qu'ils sont une seule âme en [10] des organismes dispersés ${ }^{117}$. De quelque manière que change l'état des organismes, en sa réalité, l'âme ne change pas et ne se transforme pas, ainsi que l'a dit celui qui a dit :

Dans le corps est une âme qui ne blanchit pas avec lui,

Quand bien même sur son visage, il n'y a que ruine ${ }^{118}$.

Elle garde de la jeunesse ${ }^{119}$, alors que je ne compte plus que quelques ongles,

114. Comme tu le ferais de tes biens, ainsi que l'écrit al-Ǧāhiz : « Si un ami te marque une absolue sincérité, gardele plus jalousement que le trésor le plus précieux » (Risālat al-ma'āšs, p. 57).

115. 'Azūba B : 'adūba C

116. Ou des Frères purs (Ihwān al-ṣafā').

117. Voir Plutarque, De la pluralité des amis, 96e, où les amis sont décrits : « [...] comme une seule âme dans des corps différents » (in Comment écouter ; Les moyens de distinguer ... [etc.], texte établi et traduit par R. Klaerr et al. Paris, 1989). Sur ceci, voir notre présentation, p. 317.

118. al-Mutanabbī, Dīwān, éd. Yāzīğì. Le Caire, II, 353 (cité par A. HamdanI, « The arrangement of the Rasāil Ihwān al-Safä' and the problem of interpolations ", in Journal of Semitic Studies, 29 (1984), p. 105, n. 28). Ce vers est tiré d'un poème composé en l'honneur du régent ihšīdīde al-Kāfūr en 347/958. On a souligné dans l'introduction son importance pour la datation des Rasā'il.

119. Jeu de mot sur le sens de zufur: (1) ongle ; (2) employé dans des expressions comme min nu'ūm al-zufur: depuis la tendre enfance, et connotant donc l'idée de jeunesse. On emploierait en français l'expression "elle garde bec et ongle". 
De la grandeur ${ }^{120}$ aussi, alors qu'en bouche, il ne me reste plus de dent.

Le temps change ce qu'il veut de moi, sauf elle:

J'atteins l'âge le plus avancé et elle reste les seins arrondis.

[15] Une autre caractéristique [de l'amitié des Frères de la Pureté], c'est que lorsque l'un d'entre eux agit bien envers son frère, il ne fait rien qui obligerait ce dernier, parce qu'il pense et croit que c'est envers lui-même qu'il a bien agi. Et si son frère agit mal envers lui, il ne ressent aucune aversion à son égard, parce qu'il pense que ceci s'est fait par luimême envers lui-même. Celui donc qui croit pareille chose à propos de son frère et dont le frère croit pareille chose à son propos, se sent, comme son frère, à l'abri du danger que celui-ci change à son égard un jour ou l'autre, pour une raison ou une autre, d'une façon ou d'une autre.

\section{$[49,1]$ SECTION : [LA CONSERVATION DE L'AMI]}

Lorsque tu t'es gagné un [ami], il convient que tu le préfères à l'ensemble de tes amis et de tes proches, de ton clan et de tes voisins avec lesquels tu as grandi ${ }^{121}$. Il est, en effet, meilleur pour toi que l'enfant provenant de ton dos, que le frère provenant des reins de ton père et que l'épouse à qui tu consacres tout ce que tu possèdes [5] et pour qui toute ton activité se fait. Connais donc ce à quoi il a droit de même que tu connais ce à quoi ceux-ci ont droit. Il convient même plutôt que tu le préfères à eux tous. Ceux-là, en effet, t'aiment en raison des avantages que tu leurs procures, et ils te veulent en raison des dommages que tu éloignes d'eux ${ }^{122}$. Lorsqu'ils peuvent se passer de toi, ils renoncent à toi et désirent quelqu'un d'autre ; ils te déçoivent quel que soit le besoin que tu as d'eux.

Ce frère, par contre, ne te veut pas du fait de quelque chose d'extérieur, mais parce qu'il pense et croit que tu es lui et que lui est toi, [10] une seule âme en deux organismes se faisant face ${ }^{123}$. Lui fait plaisir ce qui te fait plaisir et le peine ce qui te peine ${ }^{124}$. Il veut pour toi, de lui-même, la même chose que toi, de toi-même, tu veux pour lui ${ }^{125}$.

120. Autre jeu de mot sur le sens de nāb: (1) dent ; (2) âge, vieillesse, et donc dignité, grandeur. Nous remercions le professeur Jacques Grand'Henry pour ces précieuses indications.

121. TAWHīīi rapporte les paroles suivantes d'un bédouin à ce sujet : «L'affection que je ressens pour mon ami dépasse celle que j'ai pour mon père, ma mère, ma sœur, mon cousin, ma cousine, mon amante ... Je vois le monde par ses yeux ; je trouve chez lui ce que je cherche quand je m'approche; lorsque nous nous regardons, nous échangeons la coupe de l'amitié, et lorsque nous nous taisons, nous nous communiquons par le langage de la confiance » (Risāla fïl-ṣadāqa, éd. ğawā’ib, p. 67, cité et traduit par M. Bergé, Pour un humanisme vécu, p. 332). Plus tard, IBn Ḥazm (m. 1063) encouragera lui aussi à préférer l'ami à tout autre : «L'apogée de l'amitié [...], c'est de tout mettre en commun, sa propre personne, sa fortune, sans nulle raison contraignante, et de préférer son ami à tout autre être » (Épitre morale, trad. N. Tomiche, p. 134).

122. Sur les causes de l'amitié, divisées en essentielles et accidentelles, voir TAWHī̄Ī, al-Hawāmil wa-l-šawāmil, éd. A. Amīn et A. Șaqr, Le Caire, 1951, p. 131-133.

123. On retrouve ici une expression très proche de ce qui vient d'être dit (p. [48], 1. 9-10).

124. Iвn Hazm en fait sa définition de l'amitié : « La définition de l'amitié [...], c'est que l'un des amis souffre de ce dont souffre l'autre et qu'il se réjouisse de ce dont l'autre se réjouit » (Épître morale, p. 132).

125. C'est ce que décrit également MisKawaYH : «L'ami aime en effet son ami et veut pour lui ce qu'il veut pour sa propre personne. » Voir aussi AL-BīRūNĪ (d. 1048), Kitāb al-Ǧamāhīr, p. 18 : « [Il trouvera] son bonheur dans un ami pur [...]. Ils seront unis par l'âme et différeront par l'organisme (badan), ainsi que l'on dit à propos de l'ami qu'il est toi, sauf qu'il est différent de toi (ǵayruka). Chacun des deux s'abstiendra envers son compagnon de ce qui ne le contente pas lui-même, et aimera pour son compagnon ce qu'il désire pour lui-même. » 
Sache-le, les cœurs des meilleurs sont limpides parce que leurs âmes sont pures. Rien de ce qui est caché dans les choses ne reste dissimulé pour eux, parce que cela se donne à voir en elles, de même que ce qui apparaît de la totalité des choses se donne à voir aux yeux de ceux qui voient. Ne cèle donc pas à tes frères purs quelque chose de contraire à ce que tu leur montres, car cela ne leur resterait pas caché ni dissimulé.

\section{[15] SECTION : [LE CHOIX DES MAÎTRES]}

Sache-le, la meilleure chose qui soit octroyée à un homme est le bonheur. Or les bonheurs sont de deux sortes : intérieur et extérieur. Celui qui est intérieur est de deux sortes, l'une touchant à l'organisme, l'autre à l'âme. Celui qui touche à l'organisme, c'est comme la santé et la beauté ; celui qui touche à l'âme, comme l'acuité [de l'intelligence] et la beauté du caractère. [Le bonheur] extérieur est aussi de deux sortes : l'une est ce que la main possède, comme les biens et les jouissances d'ici-bas ; l'autre, [20] ce sont les proches parmi les fils du genre [humain], comme l'épouse, l'ami, l'enfant et le frère, le professeur et le maître, le seigneur et le sultan ${ }^{126}$.

Le plus heureux des bonheurs est qu'il t'advienne, mon frère, d'avoir un maître $[\mathbf{5 0 , 1}]$ bien dirigé, savant, connaissant les réalités des choses et des affaires, croyant au Jour du Compte, savant des prescriptions de la religion, voyant clairement ce qui concerne l'audelà, au fait des états du Retour, et qui te dirige vers cela. Par contre, la plus néfaste des infortunes est qu'il t'arrive le contraire de cela.

Sache-le, le maitre, le professeur, est un père pour ton âme ${ }^{127}$, raison de sa croissance et cause de sa vie, de même que [5] ton géniteur est un père pour ton organisme et a été raison de son existence. C'est que ton géniteur te donne une forme organique, tandis que ton maître te donne une forme spirituelle. Le maître, en effet, nourrit ton âme des sciences, l'éduque grâce aux connaissances et la guide sur le chemin de la félicité et du plaisir, de la joie, de l'éternité ${ }^{128}$ et du repos sempiternel. [Cela] de même que ton père a été raison de la génération de ton organisme dans la demeure d'ici-bas, celui qui t'a éduqué et celui qui t'a dirigé vers la recherche de la subsistance en ce monde, qui est la demeure de la disparition, du changement et de l'écoulement, heure [10] après heure. Demande à ton Seigneur, mon frère, qu'Il t'octroie un maître bien dirigé, un guide droit, et rends grâce à Dieu pour ses faveurs abondantes.

\section{SECTION : [LES FAUX SAVANTS]}

Sache-le, à propos du nomos, il est des gens qui prennent l'apparence des gens de science et qui singent les gens de religion. La philosophie, ils ne la connaissent pas; la Loi (šarīa), ils n'en connaissent pas la réalité. Et pourtant, ils prétendent malgré cela à la connaissance des réalités [15] des choses et s'adonnent à l'examen des affaires les plus absconses, obscures et lointaines, alors qu'ils ne connaissent pas leur âme, qui est la chose

126. Sur la répartition des bonheurs selon МisкаwaYh, voir Traité d'éthique, p. 129-137.

127. Voir MiskawaYh, Traité d'éthique, Livre II : Caractère et éducation.

128. Peut-être faudrait-il ici corriger le texte en al-surūr al-abadī, le texte se traduisant alors ... de la joie éternelle. 
la plus proche d'eux ${ }^{129}$, ne distinguent pas les affaires évidentes, ne réfléchissent pas sur les existants manifestes, que les sens peuvent saisir et les intelligences connaître. Ils se livrent en outre à des examens concernant le bond ${ }^{130}$, l'atome et autres questions relatives à des affaires imaginaires qui n'ont pas de réalité dans la matière (hylè), alors qu'ils doutent des choses manifestes [20] et évidentes, et prétendent à leur propos des absurdités en un discours ${ }^{131}$ vaniteux et une discussion polémique. Ainsi prétendent-ils par exemple que la diagonale du carré serait égale à un de ses côtés ${ }^{132}$, que le feu ne brûlerait pas ${ }^{133}$, que les rayons de la vue seraient un corps atteignant en un clin d'œil la sphère des astres ${ }^{134}$, que l'astrologie serait vaine ${ }^{135},[\mathbf{5 1}, \mathbf{1}]$ et autres mensonges et tromperies. Méfie-toi d'eux, mon frère. Ce sont des imposteurs à la langue facile mais aveugles de cœur ${ }^{136}$, qui doutent des réalités et dévient de ce qui est correct.

Sache-le, ils sont une épreuve pour les savants et des menteurs contre les prophètes (sur eux la paix !). [5] Ils usurpent, et ne connaissent pas en réalité ${ }^{137}$; ils prétendent ce qu'ils ne savent pas. Ils sont comme le Seigneur des mondes (majestueux est Son nom !) les a décrits [en disant] : « Mais vous, vous êtes des gens de dispute ${ }^{138}$. » Ils errent dans les oueds de ce qu'ils imaginent, disant ce qu'ils ne font pas et ne savent pas. Que Dieu nous protège ainsi que toi, mon frère, de quiconque possède ces attributs blâmables et de leur méchanceté. Ce sont des ennemis, en effet. Méfie-toi d'eux!

129. La connaissance de soi est le point de départ de toute science pour les Ihwān. Voir Rasāill, t. II, p. 462 : « Sachele, la clef de l'ensemble des sciences réside dans le fait, pour l'homme, de se connaître lui-même. » Il faut partir du plus proche, l'âme, pour ensuite avancer dans la connaissance. Pour les Ihwān, c'est Dieu lui-même qui a voulu qu'il en soit ainsi, en faisant de l'homme un microcosme. Voir en particulier l'Épître 26, Rasā̉il, t. II, p. 456-479.

130. Suit un mot que nous n'avons pu traduire : al-qlqa. Sur la théorie du bond, voir plus haut notre présentation, p. 318.

131. Kalām: c'est bien le kalām comme tel qui est ici visé.

132. Ceci en opposition à la théorie de l'incommensurabilité de la diagonale par rapport au côté, théorie déjà pythagoricienne. Voir Aristote, Métaphysique, A.2, $903 a 13$ et Euclide, Éléments, X, app. 7. Voir aussi le problème du dédoublement du carré, PLATON, Ménon, 82b-85e.

133. Sur ceci, voir plus haut notre présentation, p. 318-9.

134. Cette critique se retrouve chez ARISTote (De Sensu, 2.438a26-438b2) : « Il est totalement insensé de prétendre que voir se fait par quelque chose sortant de l'œil, et que la vue s'étend jusqu'aux astres, ou bien que, sortie de l'œil, elle se combine à une certaine distance avec la lumière extérieure, comme le disent certains » (Petits traités d'histoire naturelle, traduction R. Mugnier, Paris, 1965, p. 26). Sur les théories de la vision en islam, voir notamment G. Verbeke, Introduction à Avicenna Latinus. Liber de Anima I-II-III. Louvain - Leyde, 1972 ; A. DHAHANI, The Physical Theory of Kalām, p. 142. Selon les Iḩwān al-Ṣafā', les objets émettent des rayons dans toutes les directions, certains traversant la pupille et devenant ainsi cause de la vision. Voir Y. MARQUET, La philosophie, p. 232, et Rasā’il, t. II, p. $408-409$ et t. III, p. 106-107. Il pourrait s'agir ici également d'une critique d'al-Nažām dont la théorie du bond vient d'être évoquée, et pour qui la vision a lieu par pénétration de la vue dans l'objet (voir J. VAN Ess, Theologie und Gesellschaft. Berlin-New York, 1991-1997, t. III, p. 354-356 et A. BADAWI, Histoire de la philosophie en Islam. Paris, 1972, t. I, p. 132).

135. Sur cette critique des pourfendeurs de l'astrologie, voir plus haut, notre présentation p. 319. On retrouve dans le Sirr al-asrār la même défense de l'astrologie. Voir éd. 'A. Badawi, p. 85.

136. Voir Coran 22:46: «Ce ne sont pas les vues qui sont aveugles, mais bien les cœurs qui sont dans les poitrines. »

137. Peut-être faudrait-il ici corriger le texte et lire yantahilūna mā lā yatahaqqaqūna: « Ils usurpent ce qu'ils ne connaissent pas en réalité. »

138. Voir Coran 43:58. Le verset se lit : «Ce sont des gens de dispute. » 


\section{[10] SECTION : [LE CHOIX DES DISCIPLES]}

Sache-le, frère, avoir un maître doué d'acuité, dont la nature est excellente, les mœurs belles, l'entendement pur, qui aime le savoir, est en quête du réel et qui n'est pas fanatiquement attaché à quelque vue doctrinale, voilà qui contribue également à ton bonheur.

Sache-le, avant qu'adviennent en elles une des sciences, une des croyances, [15] les pensées des âmes sont semblables à une feuille blanche, immaculée, sur laquelle rien n'a été écrit ${ }^{139}$. Lorsque quelque chose y est écrit, que ce soit vrai ou faux, la place est occupée, ce qui empêche d'y écrire autre chose, et il est difficile de le gommer ou de l'effacer. Il en va ainsi des pensées des âmes: lorsque l'une des sciences, l'une des croyances ou une habitude leur parviennent, elles s'y établissent, qu'elles soient vraies ou fausses, et il est difficile de [les] extraire et de les effacer, ainsi que l'a dit celui qui a dit :

[20] La passion m'a touché avant que je n'aie connu la passion; elle a trouvé mon coeur vide, et s'y est établie ${ }^{140}$.

L'affaire étant telle que je l'ai décrite, ô frère, il convient que tu ne t'occupes pas de réformer [52,1] les vieillards ${ }^{141}$ décrépits qui, depuis l'enfance, ont adopté des croyances et des opinions corrompues, des habitudes mauvaises, des mœurs sauvages. Ils te fatigueraient, en effet, et ne se réformeraient pas. Et s'ils se réformaient petit à petit, ils ne réussiraient pas [totalement] ${ }^{142}$.

Tu devras te tourner plutôt vers les jeunes à la poitrine saine ${ }^{143}$, qui ont le désir des lettres, débutent dans l'examen des sciences, désirent la Voie du Réel et la Demeure dernière, croient [5] au Jour du Compte, mettent en pratique les lois des prophètes (sur eux la paix !), étudient les secrets de leurs livres, abandonnent la passion et la discussion et ne sont pas doctrinalement fanatiques.

139. ARIStote décrit l'intellect en puissance avant que les intelligibles ne lui parviennent comme une tablette sur laquelle rien n'a été écrit (De Anima, III, 4, 430a2). La même image se retrouve chez ses commentateurs comme AleXANDRe d'Aphrodise (De Anima, 3.12).

140. Dīwān Mağnūn Laylā, éd. 'Abd al-Sattār Ahmad Farāğ, Le Caire, 1973, p. 282, n² 294. Dans cette édition, comme dans l'Histoire des rois de Perse d'al-Ta'âlibī (11 ${ }^{\mathrm{e}}$ siècle, identité incertaine, peut-être 'Abd al-Malik, m. 1030; voir C. E. Bosworth, « al-Ta ālibī, Abū Manșūr », in $E I^{2}$ ) où ils sont cités (éd. et trad. H. Zotenberg. Paris, 1900, p. 74), le mot hāliyan remplace le fārigàn de notre texte. Comme dans l'édition Farāğ, Zotenberg choisit la leçon qalban au lieu de qalbī attestée dans les manuscrits généralement suivis pour le reste du texte, et traduit : «J'ai commencé à l'aimer avant de connaître l'amour qui, ayant rencontré un cœur inoccupé, s’y est installé. »

141. Le terme arabe ici utilisé (mašāyih) a aussi pour sens « šayh ».

142. Miskaway écrit dans le même sens : «Il n'y a pas de succès à attendre de qui a été élevé selon un système d'éducation différent. Il ne faut s'attacher ni à lui être utile ni à le redresser, car il est devenu tel le sanglier qu'il n'y a aucun espoir de dresser. [...] De même qu'il n'y a pas moyen de dresser des fauves sauvages qui sont inéducables, de même on ne peut discipliner quelqu'un qui a grandi dans cette voie, s'y est habitué et y a pris un peu d'âge » (Traité d'éthique, p. 104). Il tempère néanmoins son jugement en ajoutant dans la suite du texte que, parfois, on peut avoir quelque espoir dans le redressement de tels gens.

143. Voir Miskawayh, Traité d'éthique, Livre II, ch. 5 : «Sur l'éducation des jeunes et des enfants en particulier. » La raison de cette priorité à accorder à l'éducation des jeunes a été donnée plus haut. Ainsi que l'explique MisKaWAYH, "L'âme de l'enfant est naïve; nulle forme ne s'est encore gravée en elle et elle n'a pas d'opinion bien arrêtée qui la fasse pencher pour telle ou telle chose plutôt que telle autre. C'est seulement quand une forme s'est gravée en elle que l'enfant grandit sans s'en départir et s'y habitue » (Traité d'éthique, p. 93-94). 
Sache-le, Dieu le Très-Haut n'a pas envoyé de prophète qui n'ait été jeune et n'a pas donné de sagesse à un serviteur qui n'ait été jeune. Ainsi les a-t-Il évoqués et loués en disant (majestueux est Son nom !) : «Ce sont des jeunes gens qui croient en leur Seigneur, et nous leur avons donné plus de guidance » (18:13). Le Très-Haut dit aussi : « Nous avons entendu un jeune homme les mentionner. On l'appelle Abraham » (21:60). [10] Le Puissant et Majestueux dit encore : «Et Moïse dit à son jeune serviteur ${ }^{144}{ }(18: 62)$.

Les premiers à avoir accusé de mensonge chaque prophète que Dieu avait envoyé, sache-le, ont été les vieillards de leur peuple qui s'adonnaient à la philosophie, à l'étude et à la discussion. Ainsi le Très-Haut les a-t-Il décrits en disant : «Et lorsque le fils de Marie est proposé en exemple, voici que ton peuple se détourne de lui : "Nos divinités sont-elles meilleures ou bien lui ?", disent-ils. Ils ne proposent cependant [cet exemple] que pour discuter. Ce sont des gens de dispute ${ }^{145} \gg(43: 57-58)$.

[15] SECTION : [RICHESSE, SCIENCE ET PURETÉ : LA RÉPARTITION DES HOMMES FACE AUX DONS DE DIEU]

Sache-le, les dons de Dieu (majestueux est son nom !) sont multiples, innombrables. On peut les rassembler néanmoins sous deux genres, sous chacun desquels il y a de multiples espèces. L'un relève de l'organisme, l'autre de l'âme. Parmi ce qui relève de l'organisme, il $\mathrm{y}$ a les biens, et parmi ce qui relève de l'âme, la science.

Eu égard à ces deux grâces importantes, les gens se partagent quatre demeures : [20] il en est parmi eux à qui une part a été octroyée à la fois des biens et de la science ; il en est qui ont été privés des deux à la fois; il en est à qui les biens ont été octroyés mais pas la science ; il en est enfin à qui la science a été octroyée mais pas les biens.

[La possession des biens et de la science]

À chacun de nos frères auxquels ont été octroyés à la fois les biens et la science, il convient de témoigner $[\mathbf{5 3}, \mathbf{1}]$ sa reconnaissance pour ce dont Dieu (puissant et majestueux est-Il !) lui a fait grâce, en s'attachant un de ses frères parmi ceux qui ont été privés des deux à la fois. Il partagera avec lui du surplus de ce que Dieu, le Très-Haut, lui a donné comme biens, afin d'assurer la vie de son organisme dans la demeure d'ici-bas. Il lui prêtera assistance ${ }^{146}$ et lui enseignera de sa science afin que, par là, son âme soit vivifiée en vue de la permanence dans la demeure dernière. Il s'agit là, en effet, de l'un des meilleurs moyens

144. Voir Rasāil, t. IV, p. 151, où il est dit de choisir les jeunes gens, «prenant pour modèle en cela la conduite (sunna) de Dieu, le Très-Haut ». Suivent les mêmes citations coraniques que dans notre texte, sauf à la fin : « Et Moïse dit à son jeune serviteur : "Apporte-nous notre repas." "

145. Sur le rapport ou le non-rapport entre vieillesse et sagesse dans le Coran et dans la culture arabo-islamique des premiers temps, voir Daniel DE SMET, « Dieu leur prête longue vie », in Acta Orientalia Belgica, vol. XIII (2000), en particulier, p. 164.

146. Ou : ... il lui fera don (RFD). 
de se rapprocher de Dieu et d'une des manières les plus efficaces de rechercher [5] Son contentement ${ }^{147}$.

Il ne convient pas qu'il l'oblige pour ce qu'il dépense comme biens pour lui, ni qu'il le méprise. Qu'il sache plutôt que Celui qui a privé son frère est Celui-là même qui lui a donné ${ }^{148}$. De la même manière qu'il n'oblige pas un de ses fils par l'organisme pour l'éducation qu'il lui donne et pour les dépenses de biens qu'il fait pour lui, et qu'il lui donne en héritage après son décès ce qu'il a rassemblé comme biens, ainsi ne faut-il pas qu'il oblige un de ses fils par l'âme. En effet, si celui-là est son fils par l'organisme, celui-ci est [10] son fils par l'âme.

Ainsi rapporte-t-on que le Prophète (que Dieu lui accorde le salut et la paix !) a dit à 'Alī (sur lui la paix !) : « Toi et moi, nous sommes les pères de cette communauté. » Il dit aussi (que Dieu lui accorde le salut et la paix !) : « Le croyant est le frère du croyant de père et de mère ${ }^{149}$. » Abraham (sur lui la paix !) a dit : « Quiconque me suit est des miens » (14:36). Lorsque Noé (sur lui la paix!) a dit : « Mon fils est de ma famille» (11:45), le Puissant et Majestueux lui a dit : "Il n'est pas de ta famille car il a commis une action qui n'est pas vertueuse » (11:46). Le Très-Haut dit aussi : « Lorsqu'on [15] soufflera dans la Trompe, il n'y aura plus ce jour-là de lignages entre eux, et ils ne s'interrogeront point » (23:101). Il est donc manifeste que le lignage par l'organisme n'est d'aucune utilité dans l'au-delà.

C'est en ce sens que le Messie (sur lui la paix!) a dit aux Apôtres: "Je suis venu d'auprès de mon Père et de votre Père ${ }^{150}$. " Dieu, le Très-Haut, dit aussi : " La religion de votre père Abraham » (22:78). Cette paternité est par l'âme et son lignage ne s'interrompra pas, ainsi que le Prophète (sur lui la paix !) l'a dit: "Au Jour de la Résurrection, tout lignage s'interrompra sauf le mien ${ }^{151}$. » [20] Il dit aussi : « Ô Banū Hāshim, au Jour de la Résurrection, les gens viendront à moi avec leurs œuvres, tandis que vous, vous viendrez à moi avec vos lignages. Moi cependant, je ne vous préserverai en rien de Dieu ${ }^{152}$. » Ce qu'il entend par là, c'est seulement le lignage par l'organisme. Ce lignage, en effet, s'interrompt lorsque les corps périssent, tandis que le lignage par l'âme demeure, car les substances des âmes demeurent après avoir quitté les organismes.

Si [quelqu'un] pense que son fils par l'organisme vivifiera sa mémoire après sa mort, celui-là, [le fils spirituel], aussi, s'il vit, vivifiera sa mémoire dans le cercle (mağlis) des savants et en présence des gens de bien, lorsqu'il $[\mathbf{5 4 , 1 ]}$ déploiera sa science et que, se tournant vers lui, il appellera sur lui la miséricorde [divine], chaque fois qu'il l'évoquera. Ainsi, nous,

147. Un autre moyen de se rapprocher de Dieu est « de dépenser ses biens, soi-même, ses gens, pour établir la Loi (šarīa), la renforcer et la rendre manifeste » (Rasā’il, t. IV, p. 135).

148. On trouve un long passage sur les qualités du pauvre dans Rasā'il, t. III, p. 429-432. Voir trad. C. Baffioni, L'Epistola degli Ihwān al-Ṣafä' "Sulle opinioni e le religioni», Naples, 1989, p. 102-104.

149. Voir Kulayñ̄, Ușūl al-Käfî. Bāb al-īmān wa-l-kufr. Bāb uhūwat al-mu'minīn ba'ḍihim li-ba‘ḍ, nº 2, Téhéran, s.d., 4 v., vol. III, p. 241.

150. Voir Jean, 20:17. La phrase reprend des termes de l'Évangile, sans en être une citation fidèle. Cette même phrase se retrouve chez ABū Ḥ̂̄TIM AL-RĀzī, A'lām al-nubuwwa, Téhéran, 1977, p. 163, 1. 11.

151. Voir Ibn Hanbal, al-Musnad, éd. S. Majd̄̄u et S. I. Samarah, Beyrouth-Damas, 1993, vol. 4, p. 323 : « Les lignages s'interrompront au Jour de la Résurrection, sauf mon lignage »; p. 332 : « Au Jour de la Résurrection, les lignages et les liens de parenté s'interrompront, sauf mon lignage et mon lien de parenté ».

152. La-ya'tīnì : lā ya'tīn̄i BC. 
nous évoquons nos maîtres et nos professeurs plus souvent que nous n'évoquons nos pères par l'organisme et que nous n'appelons sur nos pères la miséricorde [divine].

$\mathrm{Si}$, par ailleurs, il pense que ce fils par l'organisme pourra lui être de quelque utilité lorsqu'il aura grandi et l'aidera pour les affaires d'ici-bas, il se peut que celui-là aussi en arrive dans la science, la sagesse, le bien et le rang auprès de Dieu, le Très-Haut, à pouvoir intercéder par sa science [5] pour son maître. Ce dernier sera ainsi sauvé par son intercession sans le savoir, ainsi que Dieu, le Très-Haut, l'a évoqué en disant: « De vos pères ou de vos fils, vous ne savez pas lesquels vous seront plus utiles, c'est un précepte de Dieu » (4:11).

\section{[L'échange des biens contre la science : éloge de l'entraide]}

À celui de nos frères à qui les biens ont été octroyés mais pas de science, il convient de rechercher un frère parmi ceux à qui la science a été octroyée et de se l'attacher. Le premier partagera ses biens avec le second tandis que celui-ci lui prêtera assistance par ${ }^{153}$ sa science, et ils s'entraideront l'un l'autre pour le bien de l'au-delà et de la vie d'ici-bas à la fois.

Il convient que le frère qui a des biens [10] n'oblige pas le frère qui a de la science pour ce qu'il partage comme biens avec lui et qu'il ne le méprise pas à cause de son indigence. Les biens relèvent de l'organisme en effet : c'est par eux que l'on assure la vie de l'organisme dans la demeure d'ici-bas. La science par contre est une propriété de l'âme, et c'est par elle que l'on assure la vie de l'âme dans l'au-delà. Or, la substance de l'âme est meilleure que la substance de l'organisme. La vie de l'organisme durera en effet un certain temps puis s'interrompra et périra, tandis que la vie de l'âme dans l'au-delà demeurera éternellement ${ }^{154}$, ainsi que Dieu, le Très-Haut, le rappelle : [15] « Ils n'y goûteront pas la mort sauf la première mort » (44:56).

Il convient [semblablement] que le frère qui a la science et la sagesse n'envie pas celui de ses frères qui a des biens, qu'il ne le méprise pas du fait de son ignorance, qu'il ne se vante pas devant lui de sa science et qu'il ne réclame pas de compensation pour ce qu'il lui enseigne ${ }^{155}$. Celui-là pour celui-ci par ses biens, celui-ci pour celui-là par sa science, ils sont semblables, en effet, dans leur compagnonnage et dans leur entraide, à la main et au pied dans leur jonction à l'organisme, leur service et leur entraide pour le bien-être de l'ensemble ${ }^{156}$. En effet, les mains ne réclament des pieds ni rétribution ni reconnaissance

153. Ou :... il lui fera don de (RFD).

154. Mu'abbadan B : mu'ayyadan C.

155. L'idée que la sagesse ne peut être vendue est commune chez les philosophes grecs qui s'opposent ainsi aux sophistes. Ainsi XÉNOPHON n'hésite pas à faire dire à Socrate que celui qui vend la science pour de l'argent est semblable à celui qui se prostitue, donnant sa beauté contre rémunération : "Socrate répondit : C'est une opinion reçue chez nous, Antiphon, qu'on peut faire de la beauté et de la science un emploi honteux aussi bien qu'un emploi honorable. [...] Ceux qui vendent [la science] pour de l'argent à qui veut la payer sont appelés sophistes, comme ceux qui vendent leur beauté, prostitués; mais si un homme, ayant reconnu dans un autre un heureux naturel, s'en fait un ami en lui enseignant ce qu'il sait bon, nous pensons qu'il se comporte comme il convient à un honnête citoyen " (Les Mémorables, in Euvres de Xénophon, III, trad. P. Chambry, Paris, 1967, p. 311). Sur ceci, voir L. Dugas, L'amitié antique, Paris, 1914 ( $2^{\mathrm{e} e ́ d .), ~ p . ~} 35$.

156. Mısкаwayн dit la même chose : "Chacun est dans la situation d'un des membres du corps, et le bon état de l'homme [tout entier] se fait par les membres de son corps au complet » (Traité d'éthique, p. 22). Cette image, fait remarquer M. Arkoun, se trouve déjà chez Platon, et encore plus chez les stoïciens (Traité d'éthique, p. 22, n. 2). 
lorsqu'elles [20] les chaussent d'une sandale ou qu'elles en ôtent une épine. De même, les pieds ne réclament des mains ni rétribution ni compensation lorsqu'ils les font parvenir là où elles veulent, qu'ils les mettent à l'abri et qu'elles échappent par là au danger d'être coupées. Ce sont en effet les instruments d'un seul et même organisme, et la subsistance des unes est assurée par les autres. De même aussi l'ouie n'oblige pas la vue lorsqu'elle lui fait entendre l'appel, ni la vue l'ouie lorsqu'elle lui fait voir le héraut, car ce sont deux puissances d'une seule et même âme, [55,1] chacune d'elle représentant un bien pour l'autre en leur entraide au service de l'âme et en leur obéissance [à cette dernière] dans la saisie des sensibles.

C'est ainsi qu'il convient que soit l'entraide des Frères de la Pureté dans la recherche du bien de l'au-delà et du monde d'ici-bas. En effet, l'aide du frère qui a des biens, par ses biens, au frère qui a de la science, et l'aide du frère [5] qui a de la science, par sa science, au frère qui a des biens pour le bien de l'au-delà, sont semblables à deux hommes cheminant de compagnie dans un désert ${ }^{157}$. L'un voit mais a un corps faible et a avec lui un viatique pesant qu'il ne peut porter. L'autre est aveugle mais a un corps vigoureux et n'a pas de viatique. Celui qui voit prend donc l'aveugle par la main et le conduit derrière lui, tandis que l'aveugle prend la charge de celui qui voit et la porte sur ses épaules. Partageant ainsi le viatique, ils font leur chemin et se sauvent ensemble. Aucun des deux n'a à obliger l'autre pour l'avoir sauvé de [10] la perte en l'aidant. Ils se sont en effet sauvés ensemble, chacun d'entre eux aidant son compagnon. Et il n'y a d'entraide qu'entre deux [personnes] ou plus ${ }^{158}$. Le frère ignorant est comme l'aveugle, et le frère indigent comme le faible ; le frère riche est comme le vigoureux et le frère savant comme celui qui voit. Le chemin est le compagnonnage de l'âme avec l'organisme, le désert, la vie d'ici-bas, le salut, la vie dernière. C'est à cela que sont semblables nos frères qui s'entraident pour le bien de ce monde-ci et de la vie dernière.

\section{[La science dans l'indigence : éloge de la patience]}

[15] À celui à qui la science a été octroyée et qui ne trouve personne parmi nos frères qui partagerait ses biens avec lui, il convient d'être patient et d'attendre le soulagement. Dieu (Puissant et Majestueux est-il !) ne manquera pas de l'assister par quelque chose ou quelque frère qui allègera ce qu'il supporte du fait du poids de l'indigence, ainsi qu'il l'a promis à ses amis (walì), en disant, Puissant est-il : « À qui le craint, Dieu ménage une issue et il le pourvoit d'une manière à laquelle il ne s'attendait pas » (65:2-3). Le Très-Haut dit aussi : « À celui qui le craint, Dieu facilite les choses » (65:4).

[20] Il convient aussi qu'il sache que celui à qui a été octroyée de la science est meilleur que celui à qui ont été octroyés ${ }^{159}$ des biens. La science en effet est cause de la vie de

157. MisKaWaYh utilise une autre image: « Dans tout ce qu'ils entreprennent, ils sont à l'image de quelqu'un qui ne parvient pas à déplacer un poids énorme tant qu'il s'y emploie seul, mais qui y réussit s'il se fait aider par d'autres personnes » (Traité d'éthique, p. 207).

158. Cette dernière phrase semble être une interpolation. Elle se retrouve dans les Rasā’il,t. IV, p. 169 : « Sache que ces deux choses [l'existence dans la vie de ce monde et le salut dans la vie dernière] n'arrivent et ne s'accomplissent que par l'entraide, et l'entraide n'a lieu qu'entre deux personnes ou plus. »

159. Ruziqa $\mathbf{B}$ : hurima $\mathbf{C}$... « à qui ont été refusés les biens ». 
l'âme à la fois dans la demeure d'ici-bas et dans la demeure dernière, tandis que les biens sont causes du maintien de la vie de l'organisme dans la demeure d'ici-bas seulement. Or, l'éminence de l'âme par rapport à l'organisme, la noblesse de sa substance, l'éminence de sa vie et l'éminence de son essence ont déjà été évoqués. Il convient aussi qu'il pense à celui qui a été privé à la fois des biens et de la science, afin de connaître les bienfaits que Dieu lui a dispensés et de lui rendre grâce $[\mathbf{5 6 , 1}]$ de toute façon ${ }^{160}$, de manière à être digne d'un surplus, ainsi que Dieu, le Très-Haut, l'a promis en disant : " Oui, si vous rendez grâce, je vous donnerai plus encore » (14:7).

\section{[La pureté dans l'ignorance et l'indigence : éloge de la beauté morale]}

Quant à celui de nos frères qui n'a ni biens ni science, mais qui a une âme pure, dont les mœurs sont belles, dont le cœur est sain de toute opinion corrompue, qui aime le bien et ses gens, est patient et [5] content de ce que Dieu lui a donné en partage de tout cela, il convient qu'il sache que celui à qui ont été donnés de belles mœurs, un cœur sain, l'amour du bien et le contentement devant ce qui lui est donné en partage, est meilleur que celui à qui ont été octroyés ${ }^{161}$ les biens et la science [et qui n'a pas ces qualités]. Parmi les gens, nous en trouvons en effet à qui ont été donnés la science et les biens, ou l'une de ces deux choses, mais à qui rien n'a été octroyé de ces qualités que nous venons d'évoquer. Nous trouvons en effet des groupes de savants, soi-disant philosophes, qui composent des livres sur l'amélioration des mœurs et exhortent les gens à cela, alors qu'eux-mêmes [10] sont les pires des gens pour ce qui est du caractère. Nous trouvons aussi des gens qui n'ont pas beaucoup de science mais qui ont des mœurs raffinées, ainsi que nous l'avons décrit. Il est donc manifeste que la beauté du caractère fait partie des dons de Dieu, le Très-Haut, ainsi qu'il est dit dans la tradition : «Dieu a accompli la création, les [bonnes] mœurs, la subsistance et l'échéance. » Et Dieu, le Très-Haut, a loué pour la beauté de son caractère son Prophète Muhammad (que Dieu lui accorde le salut et la paix !), lorsqu'il dit : « Assurément, tu es d'un caractère sublime » (68:4). Le Très-Haut dit aussi : "Si tu avais été rude et dur de cœur, ils se seraient dispersés d'autour de toi » (3:159). [15] Il est également dit dans la tradition : «Par la beauté du caractère, assurément, l'homme atteint dans le Jardin le degré de l'abstinent ${ }^{162}$. » La beauté du caractère fait en effet partie des manières des anges et du naturel des gens du Jardin, ainsi qu'il est rappelé dans le Coran : «Et elles s'écrièrent: “À Dieu ne plaise !, ce n'est pas un être humain ; ce ne peut être qu'un noble ange” » (12:31). La méchanceté du caractère, elle, fait partie des manières des démons et des gens du Feu qui s'envient les uns les autres, se haïssent et se maudissent les uns les autres, ainsi que Dieu, le Très-Haut, le rappelle dans le Coran: "Chaque fois qu'[20] une communauté entrera, elle maudira sa sœur » (7:38). Ils disent: " "Pas de bienvenue pour eux, ils sont exposés

\footnotetext{
160. Ou : pour tout état.

161. Nu'ima : muni'a $\mathbf{B C}$ « celui qui a été privé de biens et de science ».

162. Voir ABŪ DA’ ŪD, Kitāb al-sunan, 4798 (Ādāb. Fī husn al-khalq) : « Par la beauté de son caractère, assurément, le croyant atteint le degré de l'abstinent qui veille (al-șā̄im al-qā’im) ». Voir aussi aL-KuLAYNī, Ușūl al-kâfí. al-Īmān wa-l-kufr. Husn al-halq, 16 et 18 (éd. Téhéran, s.d., vol. 3, p. 159 et 161).
} 
au Feu !” - “À vous plutôt, pas de bienvenue”, rétorquent-ils » (38:59-60), alors qu'ils sont associés dans le tourment.

\section{[57,1] SECTION : [DES ARTISANS AUX ANGES, LA HIÉRARCHIE DES HOMMES ${ }^{163}$ ]}

Sache-le ${ }^{164}$, la puissance des âmes de nos frères concernant cette affaire ( $h \bar{a} \underline{d} \bar{a} l$-amr) que nous évoquons ${ }^{165}$ et à laquelle nous incitons, comporte quatre degrés : le premier est la pureté de la substance ${ }^{166}$ de leurs âmes, l'excellence de la réception [de l'enseignement] et la rapidité de la représentation. Il s'agit là du degré des artisans en notre cité ${ }^{167}$, que nous avons mentionnée dans la deuxième épître ${ }^{168}$. [5] C'est la puissance rationnelle qui distingue les significations des sensibles ${ }^{169}$. Elle arrive à la puissance locutive ${ }^{170}$ quinze ans après la naissance de l'organisme. C'est à cela que le Très-Haut ${ }^{171}$ a fait allusion en disant : «Lorsque ${ }^{172}$ les enfants parmi vous atteignent la puberté » (24:59). Ce sont eux que nous appelons dans nos discours ${ }^{173}$ et nos épîtres " nos frères pieux et miséricordieux ».

Au-dessus de ce degré est le degré des chefs, ceux qui ont en main la conduite [de la cité] ${ }^{174}$. Il s'agit de la déférence envers les frères, [10] de la générosité de l'âme, du don de ce qui est en surplus, de la sollicitude ${ }^{175}$, de la compassion et de l'affection à l'égard des frères. C'est la puissance de jugement ${ }^{176}$, qui arrive à la puissance rationnelle trente ans après la naissance de l'organisme. C'est à cela que le Majestueux a fait allusion en disant ${ }^{177}$ : «Lorsqu'il ${ }^{178}$ eut atteint sa maturité et fut bien formé, nous lui avons donné jugement et

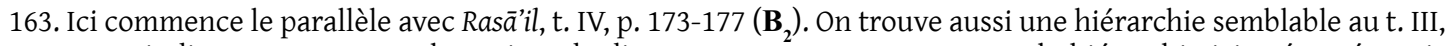
p. 195. Nous indiquerons en notes les points de divergence avec notre texte. Sur la hiérarchie ici présentée, voir notre introduction, ainsi que I. R. AL-FĀRŪQİ, « On the ethics of the Brethren of Purity », in The Muslim World, L (1960), p. 254-258; Y. MARQUET, La philosophie, p. 266-274 et « Imâmat, résurrection et hiérarchie selon les Ihwwān al-Ṣafā'», in Revue des études Islamiques, XXX (1962), p. 118-120.

164. Wa illam BC : ayyuhā l-ākh al-bārr al-rahīm + $\mathbf{B}_{2}$ « ...sache-le, ô frère pieux et miséricordieux... ».

165. Dans les Rasāill, t. IV, p. 172, il est question de l'entraide des gens de la Cité. Le terme amr que nous traduisons ici de façon neutre par « affaire » peut signifier un certain nombre de choses, depuis l'ordre (divin ou de ce monde), auquel cas il peut revêtir un sens technique précis, jusqu'à la cause (au sens de cause que l'on défend).

166. Ğawhar $\mathbf{B C}$ : ğawāhir $\mathbf{B}_{2}$ « ... de la pureté des substances... »

167. Fì madīnati-nā $\mathbf{B}_{\mathbf{2}}$ : fì madīnati-hā $\mathbf{B C}$.

168. Il s'agit de l'Épître sur la géométrie, particulièrement Rasā’il, t. I, p. 100. Sur la cité des Frères, voir Y. MARQUET, La philosophie, p. 371-378.

169. Même définition Rasā’il, t. III, p. 195.

170. Celle-ci est présente à partir de quatre ans. Elle « exprime les noms des sensibles » (Rasā’il, t. III, p. 195).

171. Ta‘ālá BC: $-\mathbf{B}_{2}$.

172. I $\underline{d} \bar{a} \mathbf{B C}: f a-i \underline{d} \bar{a} \mathbf{B}_{2}$.

173. Fì muhātâabati-nā wa- BC: $-\mathbf{B}_{2}$.

174. Al-siyāsāt BC : al-siyāsa $\mathbf{B}_{2}$. Voir Rasā’il, t. I, p. 314 : « Sache que ce qui est voulu par la conduite (siyāsa), c'est le bon état des existants et leur maintien dans le meilleur des états. »

175. Wa-l-šafaqa BC : bi-l-šafaqa $\mathbf{B}_{2}$ « ... avec sollicitude... ».

176. Celle-ci est la puissance qui « voit avec clairvoyance les significations des intelligibles » (Rasā’il, t. III, p. 195).

177. Ğalla dikru-hu bi-qawli-hi $\mathbf{B C}$ : bi-qawli-hi ta âlá $\mathbf{B}_{2}$ « ...c'est à cela que le Très-Haut a fait allusion en disant... ».

178. Fa-lammā $\mathbf{B C}:$ wa-lammā $\mathbf{B}_{2}$. 
savoir ${ }^{179} »(28: 14)$. Ce sont eux que nous appelons dans nos épîtres «nos frères bons ${ }^{180}$ et nobles ».

Le troisième degré ${ }^{181}$ au-dessus de celui-ci est le degré des rois qui possèdent l'autorité, le commandement [15] et l'interdiction, la victoire, la charge de repousser l'entêtement et l'opposition lorsque apparaît l'entêté qui s'oppose à ce commandement, cela en usant de douceur, de courtoisie et de bienveillance pour le réformer. Il s'agit de la puissance nomique, qui arrive ${ }^{182}$ quarante ans après la naissance de l'organisme. C'est à cela que [Dieu] a fait allusion en disant ${ }^{183}$ : " Quand il eut atteint la maturité et qu'il eut atteint l'âge de quarante ans, il dit: "Seigneur, permets-moi de te rendre grâce pour les bienfaits que tu m'as dispensés ${ }^{184 " ~}$ " (46:15). Ce sont eux que nous appelons " nos frères nobles et généreux ».

[20] Le quatrième [degré] est supérieur à celui-ci ${ }^{185}$.C'est celui auquel nous invitons tous nos frères, quel que soit le degré où ils se trouvent. Il s'agit de la soumission, de l'acceptation de l'appui [divin] et de la contemplation du Réel de ses propres yeux. C'est la puissance ${ }^{186}$ angélique qui arrive cinquante ans après la naissance de l'organisme. Elle prépare au Retour et à la séparation de la matière (hylè) ${ }^{187}$. C'est sur elle que descend ${ }^{188}$ la puissance de l'ascension grâce à laquelle [l'âme] s'élève vers le Royaume $[\mathbf{5 8 , 1}]$ du Ciel, contemplant alors les états de la Résurrection : l'Anastasie, la Renaissance, le Rassemblement ${ }^{189}$, le Compte, la Balance, le passage sur la Voie, le salut hors des Feux ${ }^{190}$ et le voisinage du Miséricordieux, Majestueux et Généreux.

C'est à ce degré que le Très-Haut fait allusion en disant : « Ô toi, âme apaisée, reviens vers ton Seigneur contentée et contentante, entre parmi mes serviteurs, entre dans mon Jardin ${ }^{191} »(89: 27-30)$. C'est à lui qu'a également fait allusion [5] Abraham (sur lui la paix !), selon les paroles du Très-Haut ${ }^{192}$ : « Mets-moi parmi les héritiers du Jardin de la Félicité » (26:85). C'est encore à lui que Joseph (sur lui la paix !) a fait allusion, selon les paroles du

179. On voit par cette citation que dans cette puissance, le jugement (hukm) et la sagesse (hikma) sont liés.

180. Wa- BC: $-\mathbf{B}_{2}$

181. Au t. III, p. 195, le troisième degré est celui de ceux qui ont al-quwwa al-mlkīya. Comme il s'agit du degré des rois, il s'agit sans doute de lire al-malikìya, et de traduire par « la puissance royale ». Cette puissance est caractérisée par l'appui divin, comme la quwwa malakiya de notre quatrième degré.

182. Al-wärida $\mathbf{B C}$ : 'alál-nafs $+\mathbf{B}_{2}$ « ...qui arrive à l'âme... ».

183. Bi-qawli-hi BC : ta'ālá + $\mathbf{B}_{2}$ « ... Dieu Très-Haut... ».

184. 'Alaya $\mathbf{B C}$ : wa-'alá wālidayya wa-an a mala șāliḥan tarḍ̄āhu al-āya $+\mathbf{B}_{2}$ « ... dispensés ainsi qu’à mes géniteurs et que j'accomplisse une action bonne dont tu te réjouisses, le verset ».

185. Au t. III, p. 195, le quatrième degré est celui de ceux qui ont la puissance nomique qui est dite « celle qui aplanit la [voie] du Retour, qui sépare de la matière. Elle demeure jusqu'à la fin de la vie ».

186. Al-quwwa al-malakīya $\mathbf{B}_{2}$ : quwwat al-malakìya $\mathbf{B C}$.

187. Al-mufāriqa lil-hayūlā $\mathbf{B C}$ : al-muqarriba bi-mufāraqat al-hayūlā $\mathbf{B}_{\mathbf{2}}$ «... au Retour et rapproche par la séparation d'avec la matière ».

188. Tanzilu $\mathbf{B C}:$ taridu $\mathbf{B}_{2}$ « ... sur elle que vient... »

189. Al-našr wa-l-hašr $\mathbf{B C}:$ inv. $\mathbf{B}_{2}$

190. Al-nīrān BC : wa-duhūl al-ğinān add. $\mathbf{B}_{2}$ « ... hors des Feux et l'entrée aux Jardins... ».

191. Fa-dhulī fì 'ibādì wa-dhulī jannātī $\mathbf{B C}:$ al-āya add. $\mathbf{B}_{\mathbf{2}}$ « .. mon Jardin. Le verset ».

192. Bi-qawlihi ta‘ālá $\mathbf{B C}:-\mathbf{B}_{2}$. 
Très-Haut ${ }^{193}$ : « Seigneur, tu m'as donné une part de royauté et tu m'as enseigné une part de l'interprétation des récits. Créateur des cieux et de la terre, tu es mon protecteur ici-bas et dans l'au-delà. Rappelle-moi à toi soumis (muslim) et joins-moi aux vertueux ${ }^{194}{ }$ (12:101). C'est aussi à lui que le Messie (sur lui la paix !) a fait allusion en disant ${ }^{195}$ aux Apôtres : «Lorsque je me serai séparé ${ }^{196}$ de cette carcasse, je me dresserai dans les airs à la droite du Trône, [10] devant ${ }^{197}$ mon Père et votre Père, intercédant ${ }^{198}$ pour vous. Allez vers les rois aux extrémités [de la terre], invitez-les vers Dieu, le Très-Haut ${ }^{199}$, et ne les vénérez pas. Moi, je serai avec vous où que vous alliez, avec [mon] assistance et [mon] appui ${ }^{200-201}$ » .

Notre prophète ${ }^{202}$ Muhammad (que Dieu lui accorde le salut et la paix !) y a également fait allusion ${ }^{203}$ [, en disant] : « Assurément, vous arriverez au Bassin ${ }^{204}$ demain », et [autres] traditions que l'on transmet, toutes ${ }^{205}$ bien connues des maîtres en hadīt.

Socrate aussi y a fait allusion en disant en un long discours ${ }^{206}$, le jour où le poison lui a été versé : « Même si je me sépare de vous, [15] nobles frères, je m’en vais vers des frères généreux qui nous ont précédés. » Pythagore y a fait également allusion à la fin de la Lettre dorée: «Toi, si tu fais ce que je te recommande, lors de la séparation de l'organisme, tu demeureras dans les airs, sans retourner vers l'humanité ni recevoir la mort ${ }^{207-208}$ ». C'est à

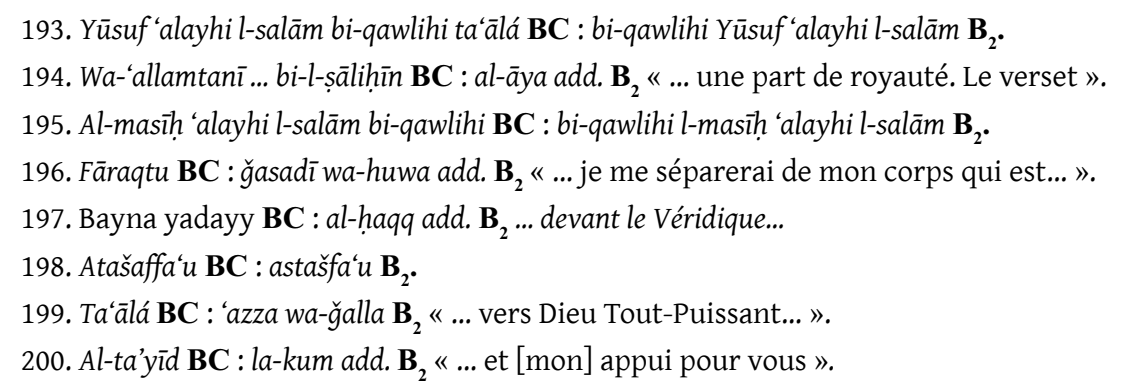

201. Voir plus haut, note 150. Cette citation se retrouve plus développée au t. IV, p. $31:$ «Il rassembla avec lui ses Apôtres dans la Cité sainte, dans une seule pièce avec ses compagnons, et dit : "Je m'en vais vers mon Père et votre Père, et je vous fais un commandement avant de me séparer de ma condition humaine (nāsūt) et je prends sur vous un pacte et un serment. Qui accepte mon commandement et remplit mon pacte sera avec moi demain, et qui n'accepte pas mon commandement, je ne suis de lui en rien et il n'est de moi en rien !" Ils lui dirent : "Quel est-il ?" Il dit : "Allez vers les rois aux extrémités [de la terre], et faites-leur parvenir de moi ce que je vous ai donné, invitez-les à ce à quoi je vous ai invités. Ne les craignez pas et ne les vénérez pas. Moi, lorsque je me serai séparé de ma condition humaine, je me dresserai dans les airs, à la droite du Trône de mon Père et de votre Père, et je serai avec vous où que vous alliez, je vous aiderai par [mon] assistance et [mon] appui, avec la permission de mon Père. » Voir Mc, 16:15; Mt 28:19-20.

202. Nabinā BC: $-\mathbf{B}_{2}$.

203. Ašāra ilayhā $\mathbf{B C}:$ inv. $\mathbf{B}_{2}$.

204. 'Alá al-hawḍ BC: $-\mathbf{B}_{2}$. Le terme n'est pas coranique, mais se retrouve dans de nombreux hadīid. Ce Bassin se trouverait avant ou, selon un plus grand nombre, après la Voie (sirātat). Parmi ses caractéristiques, il y a le fait que qui a bu de son eau n'aura plus jamais soif, que ses eaux sont plus blanches que le lait et plus douces que le miel. Voir la description qu'en fait ĠAzĀLİ, Ihyā' 'ulūm al-dīn, éd. Dār al-Rašād al-hadīta, s.d., vol. IV, p. 569. L. Gardet mentionne le fait que l'eschatologie mazdéenne connaissait déjà le réservoir ou bassin paradisiaque (L. GARDET, Dieu et la destinée de l'homme, Paris, 1967, p. 321).

205. Kullu hādihi $\mathbf{B C}$ : kulluhā $\mathbf{B}_{2}$.

206. Kalām $\mathbf{B C}:$ hadīt $\mathbf{B}_{\mathbf{2}}$ "... histoire... ».

207. Gayr 'ā'id ilá l-insìya ... lil-mawt BC : - $\mathbf{B}_{2}$.

208. Pythagore, Vers d'Or, versets 70-71. On retrouve d'autres citations de Pythagore dans les Rasāill, t. I, p. 138, t. IV, p. 35-36 et p. 175. Voir F. Rosenthal, art. « Fīthāghūrās », in $E I^{2}$. 
[ce degré] encore que Bilawhar a fait allusion [en réponse] à Yūzāsaf ${ }^{209}$. Lorsque le roi dit à son ministre, qui était des gens qui tenaient ces propos : «Dis-moi, qui es-tu? », celui-ci lui répondit en un long discours : "Je suis de ceux qui connaissent le Royaume du Ciel ${ }^{210-211}$ ».

[20] C'est à cela que nous invitons l'ensemble de nos frères, et Dieu guide qui Il veut sur une Voie droite. Le Très-Haut y a fait allusion en disant : «Dieu invite vers la demeure de la paix et guide qui Il veut sur une Voie droite ${ }^{212} »(10: 25)$. Il y a de nombreux versets en ce sens dans le Coran. Il s'agit de tout verset dans lequel il y a une description des Jardins, de leurs gens et de leur félicité.

\section{[59,1] SECTION : [LA RÉPONSE À L'INVITATION DES FRÈRES DE LA PURETÉ]}

[Les quatre états ${ }^{213}$ ]

Sache-le, ce qui est exigé de ceux qui sont invités à cela $(h \bar{a} \underline{d} \bar{a} l-a m r)^{214}$, ce sont quatre états.

Le premier est d'en affirmer la réalité ${ }^{215}$. Le deuxième, c'est le représenter en [en] donnant des paraboles, en vue de le rendre plus clair et évident. Le troisième, c'est lui donner son assentiment en conscience et conviction. Le quatrième, c'est le réaliser [5] en s'efforçant d'œuvrer d'une manière qui lui soit conforme.

Sache-le, celui qui affirme par la langue sans se représenter est un conformiste ${ }^{216}$. Celui qui se représente sans donner son assentiment est dans le doute et l'indécision. Celui qui donne son assentiment sans réaliser en s'efforçant d'œuvrer d'une manière qui lui soit conforme, [pèche] par défaut ou par excès. Celui qui traite cela de mensonge par la langue et le nie en son cœur est un opiniâtre et un mécréant, ainsi que l'a dit Dieu, le Très-Haut :

209. Le Kitāb Bilawhar wa-Yūzāsaf (ou Būdhāsaf, Būdāsaf, Būdāsf) est un ouvrage arabe puisant son sujet dans la biographie du Bouddha. Cet ouvrage a produit dans la suite le prototype de la légende chrétienne de Barlaam et Josaphat. Selon MAS'ŪDĪ, Būdāsf serait le fondateur de la doctrine des sabéens (Les prairies d'or, ch. 21 ; éd. et trad. B. de Meynard. Paris, 1861-1917, t. II, p. 111). D. GIMARET relève deux allusions dans les Rasā'il, ici et dans le passage parallèle du t. IV, p. 175, et signale d'autres emprunts outre ces références explicites (« Traces et parallèles du Kitāb Bilawhar wa Būdhāsf dans la tradition arabe », in Bulletin d'études orientales, XXIV (1971), p. 97-133).

210. Le texte semble plus clair en $\mathbf{B}_{2}$ (t. IV, p. 175) : wa-ilayhā ašāra Bilawhar ḥina qāla inna l-malik qāla li-wazìrihi wa-man ahl hādihi l-maqāla? qāla hum alladìna ya 'rafüna malakūt al-samā'. - «C'est à lui que Bilawhar a fait allusion lorsqu'il a dit que le roi dit à son ministre : "Qui sont les gens qui disent cela ?" - "Ce sont ceux qui connaissent le Royaume du Ciel", répondit-il».

211. Kitāb Bilawhar wa-Būêāsaf, éd. D. Gimaret. Beyrouth, 1972, p. 59 : « Le roi dit: "Qui sont ceux qui parlent ainsi et que disent-ils du Royaume éternel ?". Le ministre dit: "Ce sont les gens de la religion qui parlent du Royaume éternel et de la sagesse" » (trad. D. GIMARET, Le livre de Bilawhar et Būdāsf selon la version arabe ismaélienne, Genève-Paris, 1971, p. 103).

212. Wa-ilayhā ašāra bi-qawlihi ta'ālá ... șirāṭ mustaqīm $\mathbf{B C}$ : - $\mathbf{B}_{2}$.

213. Il est également question de ceci au t. I, p. 344 et au t. IV, p. 132-133. Voir aussi Y. MARQUET, La philosophie, p. 336-340.

214. Voir plus haut, note 165.

215. Al-iqrār bi-haqīa hāda l-amr $\mathbf{B C}$ : al-iqrār bi-l-lisān $\mathbf{B}_{2}$ « ... affirmer par la langue ».

216. Le conformiste (muqallid) est « comme les gens du commun, qui ne connaissent de la parole que [celle qui passe par] la gorge, de l'action que le manifeste, des sciences que des banalités, et de la religion que le fanatisme » (Rasāili, t. IV, p. 138). 
"Ceux qui ne croient pas à la vie dernière, leurs cœurs [10] sont négateurs et ce sont des orgueilleux » (16:22), "il ne fait pas de doute que le feu est pour eux et qu'ils y seront précipités » (16:62).

\section{[Les quatre caractéristiques]}

Sache-le, celui qui affirme cette affaire par la langue et qui se la représente en son cœur selon la réalité trouve en son âme quatre caractéristiques qu'il ne connaissait pas auparavant. La première est la puissance de l'âme et le fait pour elle d'émerger hors de l'organisme. La deuxième, l'ardeur dans la recherche de la délivrance hors de la matière (hylè), qui est ${ }^{217}$ la Géhenne des âmes. La troisième est l'espoir et l'espérance de la réussite et du salut lorsque l'âme se séparera de l'organisme. La quatrième, la confiance en Dieu [15] et la certitude de l'accomplissement de la chose et de son achèvement parfait.

\section{[60,1] SECTION : [LES QUATRE DEMEURES ${ }^{218}$ ]}

Sache-le, tous ceux qui confessent ce Coran, les livres des prophètes (sur eux la paix !), et ce que ceux-ci disent concernant l'invisible, se partagent à ce propos quatre demeures. Les [premiers] confessent par la langue sans assentir du cœur. Les [seconds] confessent par la langue et assentissent du cœur sans en connaître les significations et l'évidence. Les [troisièmes] confessent, [5] assentissent et en connaissent l'évidence ${ }^{219}$, mais n'assument pas les obligations qui s'y rattachent. [Les quatrièmes confessent, assentissent, sont pénétrés de son évidence et assument les obligations qui s'y rattachent.]

Celui qui confesse par la langue sans assentir du cœur est celui à qui a été octroyé peu de compréhension et de discernement. Lorsqu'il réfléchit avec son intelligence ${ }^{220}$ et distingue avec sa clairvoyance ce qu'indique l'apparence des termes des livres prophétiques, son intelligence ne l'accepte pas, parce qu'elle ne s'en représente ni les significations subtiles ni les allusions cachées. Il le nie donc du cœur et doute à son sujet.

Celui qui confesse par la langue et assentit du cœur, c'est ${ }^{221}$ celui qui réfléchit et sait qu'il ne se peut pas que n'ait point de réalité une chose si éminente, [10] sur la réalisation ${ }^{222}$ de laquelle se sont accordés les prophètes ainsi que les imams bien guidés, les califes bien dirigés et les vertueux d'entre les croyants, [quelque chose] que les nobles parmi les gens confessent ainsi que ceux qui ont du discernement et de la clairvoyance ${ }^{223}$. Sa compréhension, son discernement et son intelligence ne parviennent cependant pas à saisir l'affaire et à se la représenter en sa réalité.

217. Allad̄ì huwa $\mathbf{B C}$ : allatī hiya $\mathbf{B}_{2}$.

218. Voir aussi Rasā’il, t. I, p. 344.

219. Mutabayyin $\mathbf{B C}:$ mutayyaqin 'ārif $\mathbf{B}_{2}$ « ... assentissent, ont la certitude et connaissent... ».

220. Bi 'aqlihi BC: bi-qalbihi $\mathbf{B}_{\mathbf{2}}$ «... avec son coeur ». La différence est de taille vu les connotations attachées à chacun de ces termes.

221. $\mathrm{Fa}-\mathbf{B}_{2}$ : wa- BC.

222. Tahqiaqihi $\mathbf{B C}$ : haqiàqatihi $\mathbf{B}_{2}$ « ... sur la réalité... »

223. Voir Rasāill, t. IV, p. 37 : «Qu'en penses-tu? Les gens de toutes les religions se seraient-ils donc accordés sur des choses qui n'auraient pas de réalité? » 
Celui qui en connaît l'évidence mais est déficient pour ce qui est de mettre en œuvre ce qu'elle implique, c'est celui à qui Dieu a donné le succès et qu'il dirige, qui est guidé par les réalités de ces secrets mentionnés dans les livres [15] des prophètes (sur eux la paix !), mais qui ne trouve personne pour l'aider à faire triompher [cette cause] et à accomplir les obligations qui s'y rattachent. Il est seul en effet, et toute chose ne s'accomplit pas solitairement ${ }^{224}$, mais requiert parfois au contraire de réunir beaucoup [de gens], et particulièrement ce qui concerne le nomos. Le minimum requis, ce sont quarante caractéristiques, réunies en une seule et même personne ou en quarante personnes ${ }^{225}$ aux cœurs alliés ${ }^{226}$.

Fin de l'épître sur le comment des relations des Frères de la Pureté. Elle est suivie de l'épître sur ce qu'est [20] la foi et sur les caractéristiques des croyants qui réalisent.

224. Bi-l-wah̆da $\mathbf{B C}$ : bi-wāhid min al-nās $\mathbf{B}_{2}$ «... ne s'accomplit pas par un seul homme ». En effet, «il n'est pas possible que toutes les qualités [dont l'homme a besoin pour être accompli] soient réunies en un seul individu, et c'est pour cette raison qu'elles sont dispersées dans l'ensemble des individus humains ». C'est une idée que développe également Miskawayн. Voir son Traité d'éthique, p. $239:$ : Il est impossible à celui qui est complet par autrui d'accéder à son bonheur accompli dans la solitude et dans l'isolement. »

225. Sur le nombre quarante dans ce contexte, voir Rasā̉il, t. I, p. 376-377, où les Ihwān citent une tradition prophétique disant : « Il ne manquera pas en cette communauté de quarante hommes d'entre les valeureux qui seront de la religion d'Abraham, le Bien Aimé, sur lui la paix. » Voir aussi Y. MARQUET, La philosophie, p. 441.

226. Voir Rasā'il, t. IV, p. 125-126, où les Ihwān décrivent le sort de la communauté après la mort de son prophète. Les attributs et qualités du prophète sont soit réunis en un seul, celui-ci devenant alors le calife du Prophète dans la communauté, soit dispersés entre les membres de la communauté, ceux-ci se réunissant alors pour ne plus former qu'un seul homme et qu'une seule âme dans leur recherche du salut. Les Ihwān citent à ce propos une tradition selon laquelle le Prophète aurait dit : «Les croyants sont comme un seul homme et une seule âme. » 